\title{
Adiabatic and Diabatic Signatures of Ocean Temperature Variability
}

\author{
R. M. HOLMES, ${ }^{\mathrm{a}, \mathrm{b}, \mathrm{c}}$ T. SOHAIL, ${ }^{\mathrm{c}}$ AND J. D. ZIKA ${ }^{\mathrm{c}}$ \\ ${ }^{a}$ Climate Change Research Centre, University of New South Wales, Sydney, Australia \\ ${ }^{\mathrm{b}}$ Australian Research Council Centre of Excellence for Climate Extremes, University of New South Wales, Sydney, Australia \\ ${ }^{\mathrm{c}}$ School of Mathematics and Statistics, University of New South Wales, Sydney, Australia
}

(Manuscript received 2 September 2021, in final form 9 November 2021)

\begin{abstract}
Anthropogenically induced radiative imbalances in the climate system lead to a slow accumulation of heat in the ocean. This warming is often obscured by natural modes of climate variability such as El Niño-Southern Oscillation (ENSO), which drive substantial ocean temperature changes as a function of depth and latitude. The use of watermass coordinates has been proposed to help isolate forced signals and filter out fast adiabatic processes associated with modes of variability. However, how much natural modes of variability project into these different coordinate systems has not been quantified. Here we apply a rigorous framework to quantify ocean temperature variability using both a quasi-Lagrangian, watermass-based temperature coordinate and Eulerian depth and latitude coordinates in a free-running climate model under preindustrial conditions. The temperature-based coordinate removes the adiabatic component of ENSO-dominated interannual variability by definition, but a substantial diabatic signal remains. At slower (decadal to centennial) frequencies, variability in the temperature- and depth-based coordinates is comparable. Spectral analysis of temperature tendencies reveals the dominance of advective processes in latitude and depth coordinates while the variability in temperature coordinates is related closely to the surface forcing. Diabatic mixing processes play an important role at slower frequencies where quasi-steady-state balances emerge between forcing and mixing in temperature, advection and mixing in depth, and forcing and advection in latitude. While watermass-based analyses highlight diabatic effects by removing adiabatic variability, our work shows that natural variability has a strong diabatic component and cannot be ignored in the analysis of longterm trends.
\end{abstract}

SIGNIFICANCE STATEMENT: Quantifying the ocean warming associated with anthropogenically induced radiative imbalances in the climate system can be challenging due to the superposition with modes of internal climate variability such as El Niño. One method proposed to address this issue is the analysis of temperature changes in fluidfollowing (or "watermass") coordinates that filter out fast adiabatic processes associated with these modes of variability. In this study we compare a watermass-based analysis with more traditional analyses of temperature changes at fixed depth and latitude to show that even natural modes of climate variability exhibit a substantial signal in watermass coordinates, particularly at decadal and slower frequencies. This natural variability must be taken into account when analyzing long-term temperature trends in the ocean.

KEYWORDS: Mixing; Ocean dynamics; Water masses/storage; Heat budgets/fluxes; Climate models; Climate variability

\section{Introduction}

The slow but inevitable absorption by the ocean of excess energy accumulating in the Earth system due to greenhouse gas emissions (von Schuckmann et al. 2020) is punctuated by interannual and decadal oscillations. El Niño-Southern Oscillation (ENSO) is a key driver of interannual variations in sea surface temperature (SST), air-sea heat fluxes and global ocean heat content (OHC; Roemmich and Gilson 2011; Mayer et al. 2016; Johnson and Birnbaum 2017; Cheng et al. 2019; Trenberth 2020). The "global warming hiatus" at the turn of the twenty-first century, where the rate of increase of global mean SST was significantly reduced, is thought to be associated with natural modes of

Holmes current affiliation: School of Geosciences, University of Sydney, Sydney, Australia.

Corresponding author: Ryan Holmes, r.holmes@sydney.edu.au decadal variability, particularly in the tropical Pacific (Drijfhout et al. 2014; England et al. 2014; Kosaka and Xie 2016). The three-dimensional evolution of OHC over these events is complex, involving a range of processes and scales. Given a sparse observing system, biases in global climate models and the inherent chaotic nature of the climate system, quantifying $\mathrm{OHC}$ change (whether forced or natural) and understanding the driving mechanisms is a challenge.

Conventionally, ocean temperature change is distilled by averaging in an Eulerian coordinate such as depth or latitude. Depth-coordinate analyses have shown that ENSO dominates the signal of variability in recent decades superimposed on top of a relatively small but apparent long-term warming signal (Roemmich and Gilson 2011; Roemmich et al. 2015). Latitude-based analyses have highlighted substantial warming in the Southern Ocean and cooling in the North Atlantic likely driven by large-scale changes and/or variability in ocean circulation (Bryden et al. 2020; Rathore et al. 2020; Zika et al. 2021). 
Watermass-based analyses have been proposed as a useful tool to address sampling issues and separate internal variability from forced trends. Since watermass-based coordinates are quasi-Lagrangian, they filter out fast, adiabatic (heat/salt conserving) and often wind-driven motions leaving, presumably, a more robust and less noisy signal (Stevenson and Niiler 1983; Jayne and Marotzke 2001; Palmer et al. 2007; Toole et al. 2004; Palmer and Haines 2009; Palmer et al. 2009; Zika et al. 2015). For example, Palmer et al. (2007, 2009) compared observed and modeled ocean temperature variability and trends averaged above the watermass-following $14^{\circ} \mathrm{C}$ isotherm and the Eulerian 220-m depth surface, respectively, showing that both interannual and decadal time-scale variability was reduced in the temperature-coordinate analysis and the long-term warming trend was more robustly identifiable. Watermass-based analyses also have other advantages. For instance, budget analyses (such as heat or salt budgets) performed in watermass coordinates can be simpler than Eulerian budgets because only smoother diabatic terms are present. Attribution of model biases to the representation of specific processes is then easier. A focus on diabatic processes is useful as the adiabatic redistribution of $\mathrm{OHC}$ is more easily reversed when the forcing returns to its original state. For example, in experiments motivated by the global warming hiatus, Maher et al. (2017) found that a symmetric cycle of decadal wind stress trends applied in the tropical Pacific resulted in $\mathrm{OHC}$ changes that were largely reversible, but that residual anomalies remained that were linked to either heat transport through the Indonesian Throughflow or diabatic diffusive mixing across the Pacific thermocline. The purpose of this article is to quantify the differing projections of $\mathrm{OHC}$ variability into Eulerian depth and latitude coordinates, to which adiabatic processes contribute, and into a purely diabatic watermass-based temperature coordinate.

Comparing $\mathrm{OHC}$ variability between depth and temperature-based coordinates presents some challenges. For example, the volumes of temperature and depth layers differ, and in the case of temperature, change with time. This can introduce ambiguity as variations in heat content and temperature can become decoupled. In this article, we address this problem by using a volume percentile approach where we consider layers constructed a priori to have a constant volume (this method was introduced as the tracer-percentile framework by Sohail et al. 2021). Using this volume percentile approach (described in section 3) we compare the internal variability of OHC derived from a modern coupled climate model (ACCESS$\mathrm{CM} 2$, section 2) in a watermass-based temperature coordinate [governed by the diathermal heat transport budget; Hieronymus et al. (2014); Holmes et al. (2019); Sohail et al. (2021)] to Eulerian depth [governed by the vertical heat transport budget; Gregory (2000); Wolfe et al. (2008)] and latitude [governed by the meridional heat transport budget; Trenberth and Caron (2001)] coordinates. Our analysis (described in section 4) suggests that variability at interannual frequencies, largely associated with ENSO, projects into both the Eulerian depth and watermassbased temperature coordinates, with the adiabatic component removed in the temperature-coordinate analysis (thus reducing variability). In contrast, at decadal to centennial frequencies, where variations in the global meridional overturning circulation (GMOC) are prominent, OHC variability in the diabatic temperature coordinate is comparable to that in the Eulerian depth coordinate. We discuss the implications of these results for estimating global $\mathrm{OHC}$ trends in section 5, with conclusions summarized in section 6 .

\section{Climate model data: ACCESS-CM2}

Our analysis focuses on the 650-yr preindustrial (PI) control simulation of the CMIP6 (Eyring et al. 2016) ACCESSCM2 climate model (Bi et al. 2020), whose ocean model component is the Modular Ocean Model, version 5.1 (Griffies 2012). ACCESS-CM2 uses Conservative Temperature as its temperature variable (McDougall 2003; McDougall and Barker 2011). The ocean component uses a nominal $1^{\circ}$ horizontal resolution grid with a refinement to $1 / 3^{\circ}$ in latitude near the equator, and 50 vertical levels with $10-\mathrm{m}$ spacing in the upper ocean. Small-scale vertical mixing is parameterized using KPP (Large et al. 1994), a bottom-intensified tidal-mixing scheme (Simmons et al. 2004) and a latitudinally varying background diffusivity (Jochum 2009). Lateral eddy transport and tracer diffusion are parameterized following Gent and McWilliams (1990); Griffies (2012); Redi (1982); Griffies et al. (1998). More details on the model and spinup strategy are contained in Bi et al. (2020).

For temperature-coordinate calculations monthly average heat content, volume, and heat budget tendency terms are binned into $0.05^{\circ} \mathrm{C}$ temperature bins, prior to being interpolated onto a uniform volume-percentile grid with $0.25 \%$ spacing (see section 3). The fine $0.05^{\circ} \mathrm{C}$ bin size (compared to the $0.5^{\circ} \mathrm{C}$ used elsewhere, Holmes et al. 2019) is used in order to resolve variability in the cold range where temperature contrasts are weak, reducing noise when interpolating into percentiles. For latitude and depth coordinates the equivalent calculations are trivially achieved by summing along the native model grid dimensions and then interpolating onto the same uniform volume-percentile grid with $0.25 \%$ spacing.

Anomalies associated with internal modes of variability are obtained by dropping the first 50 years of the monthly averaged data where there is more rapid OHC adjustment, detrending (after interpolating into percentile coordinates) using a cubic fit following Irving et al. (2020, these trends are of order $0.001^{\circ} \mathrm{C} \mathrm{yr}^{-1}$ ) and then removing the seasonal cycle. Monthly averaged heat budget terms, which are time tendencies, are time integrated before being detrended and deseasoned.

\section{Theory and ACCESS-CM2 time-mean state}

\section{a. Volume percentile coordinates}

To cleanly compare between depth, latitude and temperature coordinates our analysis is done using volume percentiles, which were introduced by Sohail et al. (2021) for the temperaturecoordinate case. For the temperature, depth, and latitude coordinates used in this article, the corresponding volume percentiles are defined by 


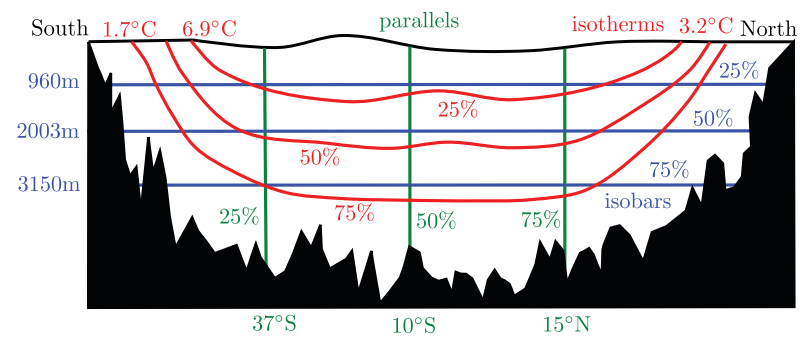

FIG. 1. A schematic illustrating the temperature (red isotherms), depth (blue isobars), and latitude (green parallels) volume percentile frameworks. The percentile surfaces bounding the warmest (red), shallowest (blue), or southernmost (green) $25 \%, 50 \%$, and $75 \%$ of the ocean by volume are illustrated approximately for each framework. For the ACCESS-CM2 PI Control long-term mean the temperature $\left({ }^{\circ} \mathrm{C}\right)$, depth $(\mathrm{m})$, and latitude $\left({ }^{\circ}\right)$ of these surfaces are labeled.

$$
\begin{aligned}
& p_{\Theta}\left(\Theta^{*}, t\right) \equiv \frac{100}{V} \iiint_{\Theta(x, y, z, t)>\Theta^{*}} d V, \\
& p_{z}\left(z^{*}, t\right) \equiv \frac{100}{V} \iiint_{z<z^{*}} d V, \\
& p_{\phi}\left(\phi^{*}, t\right) \equiv \frac{100}{V} \iiint_{\phi<\phi^{*}} d V,
\end{aligned}
$$

where $t$ is time, $V$ is the total volume of the ocean ( $V$ is approximately constant and is assumed as such throughout this article, although variations could easily be accounted for, see Sohail et al. 2021) and $d V$ is a volume element (e.g., a model grid cell). The temperature percentile $p_{\Theta}$ in Eq. (1) is defined using an integral over the volume of ocean warmer than the temperature $\Theta^{*}$ [where $\Theta(x, y, z, t)$ is the threedimensional Eulerian temperature field]. The depth percentile $p_{z}$ in Eq. (2) is defined using an integral over the volume of ocean shallower than the depth $z^{*}$ (where $z$ is depth increasing downward). The latitude percentile $p_{\phi}$ in Eq. (3) is defined using an integral over the volume of ocean south of the latitude $\phi^{*}$. The percentiles $p_{\Theta}, p_{z}$, and $p_{\phi}$ increase from $0 \%$ to $100 \%$ of the total volume $V$ (see Fig. 1).

As $p_{\Theta}$ is a monotonic function of $\Theta^{*}$ it can be inverted to yield the temperature of the isotherm that bounds the warmest $p / 100$ fraction of the ocean (where $p$ is now an independent variable):

$$
p_{\Theta}\left(\Theta^{*}, t\right) \Leftrightarrow \Theta_{\Theta}(p, t)
$$

This operation allows variations in the volume and heat content of layers bounded by isotherms to be conveniently cast in terms of temperature (i.e., heat content per unit volume) anomalies. Moreover, temperature anomalies in this temperature-based coordinate [i.e. $\Theta_{\Theta}^{\prime}(p, t)$, where the prime indicates a temporal anomaly] can be compared to temperature anomalies $\Theta_{z}^{\prime}(p, t)$ and $\Theta_{\phi}^{\prime}(p, t)$ in the depth- and latitudebased coordinates, respectively, where $\Theta_{z}(p, t)$ is the average temperature at a depth that bounds the upper $p$ percent of the ocean by volume [e.g., $\Theta_{z}(0, t)$ is the global average SST] and $\Theta_{\phi}(p, t)$ is the depth- and longitude-averaged temperature at the latitude that bounds the southernmost $p$ percent of the ocean volume. Moreover, this comparison is unambiguous as the volumes considered are constant, unlike for a regular temperature coordinate (see appendix A for a more detailed demonstration of how volume variability leads to issues with a regular temperature coordinate). The time-mean percentile coordinate transformations along with the time-mean temperature profiles $\overline{\Theta_{\Theta}}(p), \overline{\Theta_{z}}(p)$, and $\overline{\Theta_{\phi}}(p)$, where the overline indicates a time mean, from ACCESS-CM2 are shown in Fig. 2. Note that throughout the results section of the article we will consider only deseasoned and dedrifted temperature anomalies and drop the prime accordingly. The temperature profiles $\Theta_{C}$ are related to the cumulative $\mathrm{OHC}$ in the percentile coordinates through

$$
\mathcal{H}_{C}(p, t)=0.01 \rho_{0} c_{p} V \int_{0}^{p} \Theta_{C}\left(p^{\prime}, t\right) d p^{\prime}
$$

where $\rho_{0}$ is a constant reference density, $c_{p}$ is the specific heat capacity, and $C$ is either temperature $\Theta$, depth $z$, or latitude $\phi$.

\section{b. Heat budgets}

Global heat budgets in the three coordinates introduced above can be summarized as

$$
\begin{aligned}
& \frac{\partial \mathcal{H}_{\Theta}}{\partial t}(p, t)=\mathcal{F}_{\Theta}+\mathcal{M}_{\Theta}, \\
& \frac{\partial \mathcal{H}_{z}}{\partial t}(p, t)=\mathcal{F}_{z}+\mathcal{M}_{z}+\mathcal{A}_{z}, \\
& \frac{\partial \mathcal{H}_{\phi}}{\partial t}(p, t)=\mathcal{F}_{\phi}+\mathcal{M}_{\phi}+\mathcal{A}_{\phi} .
\end{aligned}
$$

In Eqs. (6)-(8) we have grouped the process contributions to the tendency in the cumulative heat content in percentile coordinates [lhs, time derivative of Eq. (5)] into terms associated with surface forcing $\mathcal{F}$, mixing $\mathcal{M}$, and advection $\mathcal{A}$. The terms in Eqs. (6)-(8) are calculated from the corresponding terms in the MOM5 gridcell heat budget diagnostics (described in more detail in Holmes et al. 2019; Griffies 2012; Dias et al. 2020) output as monthly averages, summed globally in temperature, depth or latitude coordinates and then interpolated onto the percentile grid with $0.25 \%$ spacing.

The heat budget in temperature-percentile coordinates [Eq. (6)] is characterized by a balance between the two purely diabatic processes; surface forcing and mixing. Adiabatic processes do not influence the heat content of ocean volumes bounded only by temperature, or temperature-percentile, surfaces. Furthermore, in temperature-percentile coordinates the problematic across-isotherm heat flux associated with acrossisotherm volume fluxes, which would be the contribution of advection to Eq. (6) and motivated the "internal heat 

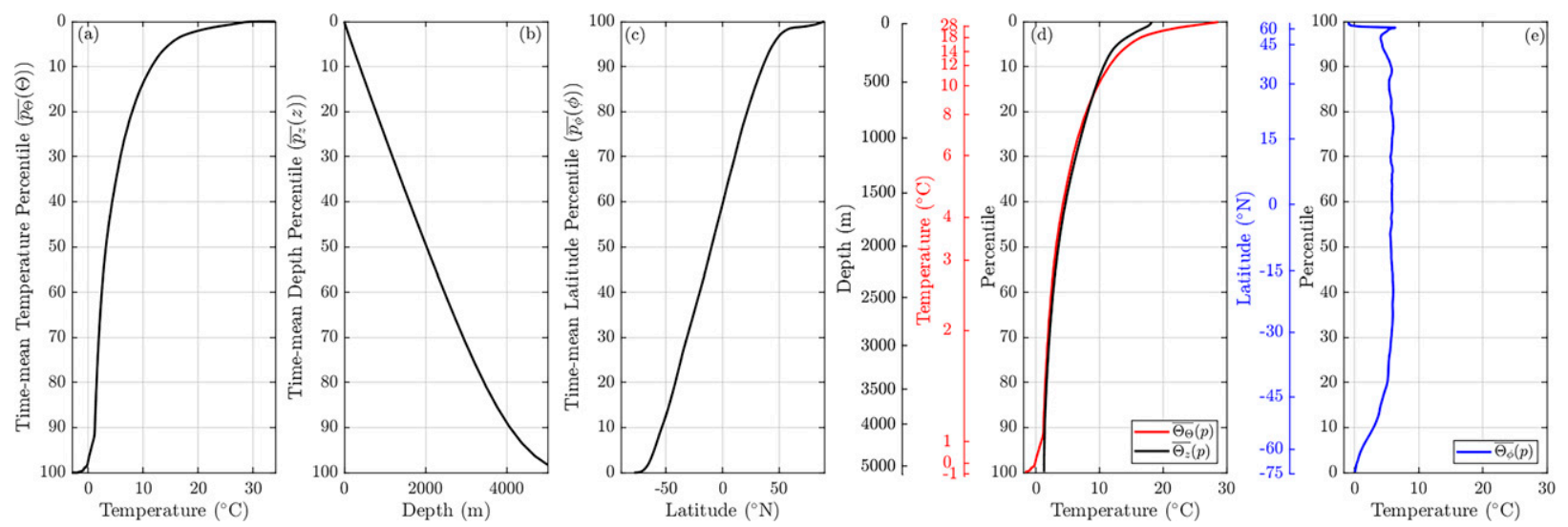

FIG. 2. Time-mean profiles of (a) temperature, (b) depth, and (c) latitude percentiles calculated following Eqs. (1)-(3) from ACCESSCM2. The percentile-coordinate transformation is relatively linear for depth and latitude except in the abyssal ocean and at high latitudes. For temperature almost $90 \%$ of the ocean's volume lies between temperatures of $0^{\circ}$ and $10^{\circ} \mathrm{C}$. Time-mean profiles of temperature in (d) depth- (black), temperature- (red), and (e) latitude-percentile coordinates from the ACCESS-CM2 PI Control simulation. The percentile coordinates are ordered from warm to cold, the surface to depth, and from south to north as percentile increases.

content" approach of Holmes et al. (2019), is removed by construction as the volumes considered are constant. Specifically, advection does not contribute to Eq. (6) because 1) the bounding $p_{\Theta}$ surface is a surface of uniform temperature and thus there are no correlations between temperature anomalies $\left(\Theta^{\prime}\right)$ and diasurface velocity anomalies $\left(\mathbf{u}^{\prime}\right)$ on the surface (that could lead to a diasurface "eddy" advective heat flux $\overline{\Theta^{\prime} \mathbf{u}^{\prime}}$ ) and 2) the total volume flux across the $p_{\Theta}$ surface (that could lead to a diasurface heat flux $\bar{\Theta} \overline{\mathbf{u}}$ ) can only be associated with surface volume fluxes by construction and is thus small (and absorbed into $\mathcal{F}_{\Theta}$ ). The role of surface volume fluxes in Eq. (6) is discussed in more detail in appendix B.

For ACCESS-CM2, the time mean of the temperaturecoordinate budget Eq. (6), corresponding to a remapping of the internal heat content budget of Holmes et al. (2019), is illustrated in Fig. 3a. The surface forcing term $\mathcal{F}_{\Theta}$ (black line in Fig. 3a) includes all surface atmosphere-ocean and sea iceocean heat fluxes (including the "internal" component of the surface heat flux due to surface volume fluxes, see appendix B and Holmes et al. 2019). Surface forcing acts to increase

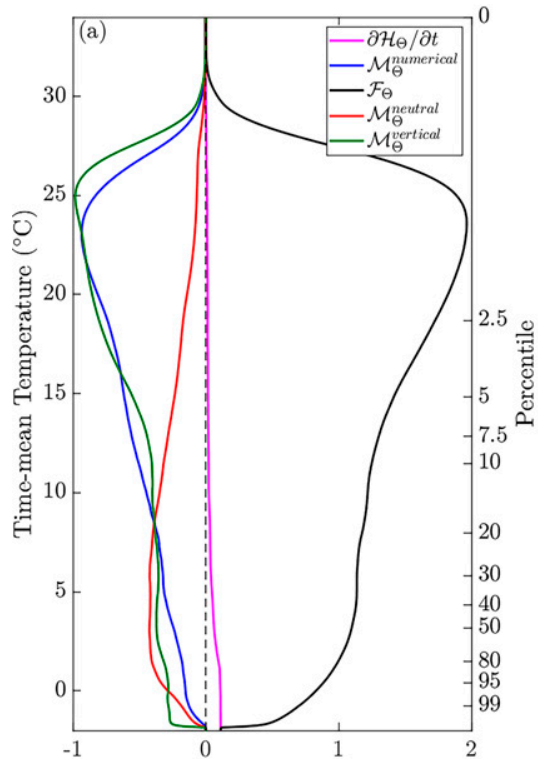

Cold-to-warm Diathermal heat transport (PW)
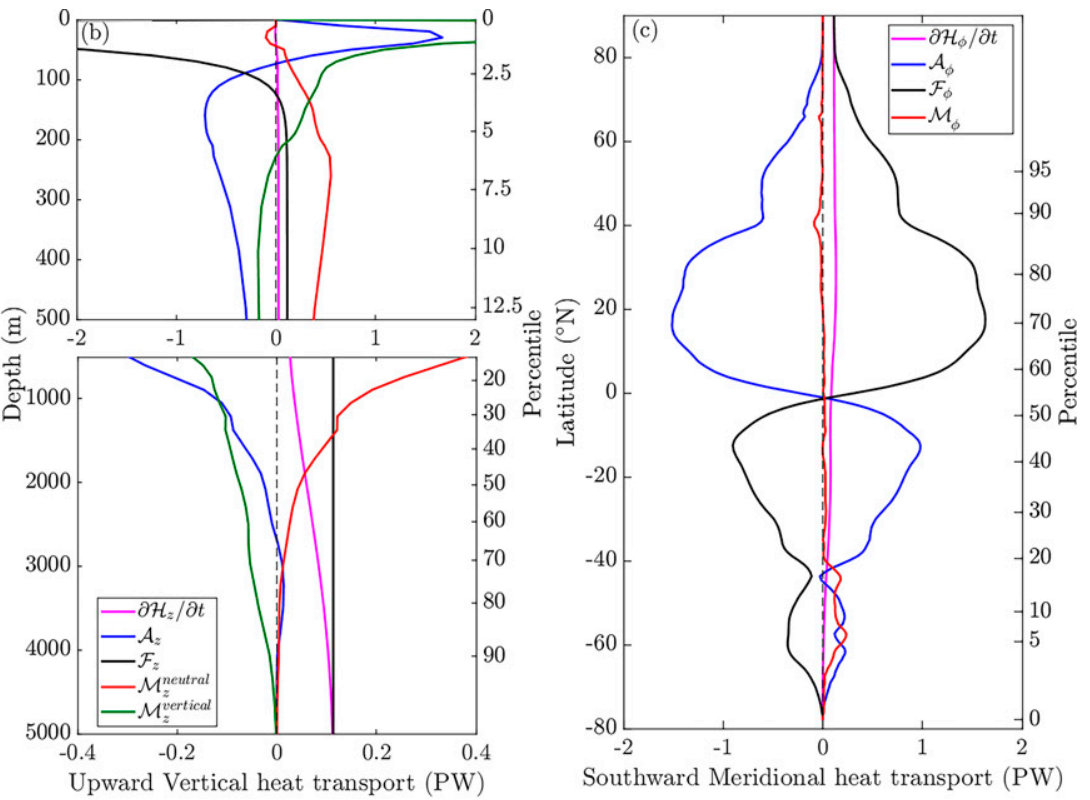

FIG. 3. The ACCESS-CM2 PI control time-mean heat budgets in (a) temperature- [Eq. (6)], (b) depth- [Eq. (7)], and (c) latitude-percentile [Eq. (8)] coordinates plotted with a linear time-mean source coordinate for ease of interpretation. The corresponding percentile is shown on the right axis for each coordinate. Positive values characterize (a) cold-to-warm, (b) upward, and (c) southward heat transport, respectively. 
temperature contrasts in the ocean by warming warm waters and cooling cold waters (hence its effects are "upgradient," positive in Fig. 3a). The surface forcing is balanced by mixing $\mathcal{M}_{\Theta}$, which fluxes heat downgradient. In Fig. 3a the mixing term $\mathcal{M}_{\Theta}$ has been split into three components associated with:

- Small-scale vertical mixing $\left(\mathcal{M}_{\Theta}^{\mathrm{vertical}}\right.$, green line in Fig. 3a), parameterized in ACCESS-CM2 using a small-scale vertical diffusivity and surface boundary layer nonlocal fluxes following Large et al. (1994), Simmons et al. (2004), and Jochum (2009).

- Neutral mixing $\left(\mathcal{M}_{\Theta}^{\text {neutral }}\right.$, red line in Fig. 3a), explicitly parameterized using an along-isopycnal diffusivity (Solomon 1971; Redi 1982; Griffies et al. 1998). Note that the direct effect of along-isopycnal diffusion on the temperaturecoordinate heat budget is a key difference between using a temperature- compared to a density-based watermass coordinate.

- Numerical mixing associated with truncation errors in the model advection scheme $\left(\mathcal{M}_{\Theta}^{\text {numerical }}\right.$, blue line in Fig. 3a). Numerical mixing is calculated by residual and discussed in more detail in Holmes et al. (2019, 2021a). Note that here numerical mixing also includes the effects of sub-monthly variability that is not captured by the offline monthly averaged binning into temperature coordinates performed for ACCESS-CM2 (unlike in Holmes et al. 2019, 2021a, where binning was done online). However, by comparing offline and online binning in ocean-only MOM5 configurations we have found that these sub-monthly correlations are small for coarse $1^{\circ}$ simulations (such as ACCESS-CM2) where eddy variability is weak (not shown).

The heat budget in depth-percentile coordinates [Eq. (7), illustrated for ACCESS-CM2 in Fig. 3b] is a balance between surface heat fluxes, $\mathcal{F}_{z}$ (which is a constant below the shortwave radiation absorption layer, black line in Fig. 3b), and the vertical heat flux across the $p_{z}$ depth due to mixing, $\mathcal{M}_{z}$, and advective processes $\mathcal{A}_{z}$. Mixing here includes both vertical mixing and the vertical component of parameterized neutral mixing, while advection includes both parameterized (Gent and McWilliams 1990) and resolved vertical eddy heat fluxes as well as the vertical heat flux due to the mean circulation. Note that numerical mixing does not contribute to Eq. (7) because it only mixes heat within grid cells not across grid cell boundaries (Holmes et al. 2021a). This budget corresponds to a remapped version of the vertical heat budget as discussed previously in the literature (e.g., Gregory 2000; Wolfe et al. 2008; Morrison et al. 2013; Griffies et al. 2015; Dias et al. 2020). ACCESS-CM2 shows similar general features highlighted by these previous studies. There is a surface layer balance between the downward flux from shortwave penetration and upward fluxes due to parameterized boundary layer convection (here included in $\mathcal{M}_{z}$ ) and advection. In the interior the downward heat transport via advection and vertical mixing is balanced by an upward heat transport via parameterized neutral diffusion. The positive tendency term (magenta in Fig. 3b) indicates a warming drift in the deep ocean.
Finally, the heat budget in latitude-percentile coordinates [Eq. (8), illustrated for ACCESS-CM2 in Fig. 3c, also see Trenberth and Caron 2001] captures the balance between the cumulatively integrated surface heat fluxes, $\mathcal{F}_{\phi}$ (black line in Fig. 3c) and meridional ocean heat transport which includes both advective, $\mathcal{A}_{\phi}$ (including both eddy and mean components), and diffusive, $\mathcal{M}_{\phi}$ (associated with neutral diffusion), components (blue and red lines in Fig. 3c). Heat is fluxed poleward by the ocean circulation in order to balance low-latitude surface heat gain and high-latitude surface heat loss. In ACCESS-CM2 the ocean heat transport associated with parameterized neutral diffusion plays a significant role only in the Southern Ocean south of $40^{\circ} \mathrm{S}$.

Each budget described above comprises a balance between different adiabatic and diabatic processes. In the temperature coordinate the budget is purely diabatic, while in the latitude and depth coordinates there is a mix of adiabatic and diabatic processes. In steady state, diabatic and adiabatic processes are closely linked. For example, no heat transport in any of the three coordinates is possible in a steady state without diabatic processes. However, variability in adiabatic processes can drive heat content variability in depth (e.g., vertical heaving of isotherms via $\mathcal{A}_{z}$ ) and latitude (e.g., meridional redistribution of heat via $\mathcal{A}_{\phi}$ ) coordinates, but not in temperature coordinates. Variability in these budgets will be examined in the following section, after a discussion of the temperature variability itself.

\section{Results: Internal variability in the ACCESS-CM2 PI control simulation}

We begin by examining dedrifted, deseasoned temperature anomalies from the ACCESS-CM2 PI control experiment (Fig. 4, where Fig. 5 summarizes the amplitude of the variability in each coordinate). Variability is prominent at all latitudes (Fig. 4c, blue line in Fig. 5b), but is surface intensified and weakens with depth, particularly below $2000 \mathrm{~m}$ ( $p \sim 45 \%$ in Fig. 4a, black line in Fig. 5a). There are clear transitions between interannual variability associated with ENSO, which is prominent in the upper $250 \mathrm{~m}(p<5 \%$ in the inset in Fig. 4a, see section $4 a)$ and near the equator $(50 \%<p<70 \%$ in the inset in Fig. 4c), and the decadal to centennial variability that is dominant at depth and outside of the equatorial region.

In the diabatic temperature coordinate, variability is stronger at the warmer temperatures where there is evidence of both interannual and decadal to centennial frequency variability (Fig. 4b). While this variability has a different character to the adiabatic depth coordinate, it is remarkable how comparable the variability amplitude in depth and temperature coordinates are over the majority of the ocean's volume between $10 \%<p<90 \%$ (cf. black and red lines in Fig. 5a), where decadal-to-centennial frequencies dominate. There is also a prominent low-frequency signal at the coldest temperatures corresponding to the cold polar surface waters (below $\sim 1^{\circ} \mathrm{C}, p>90 \%$ ), which will be discussed in section $4 \mathrm{~b}$. 

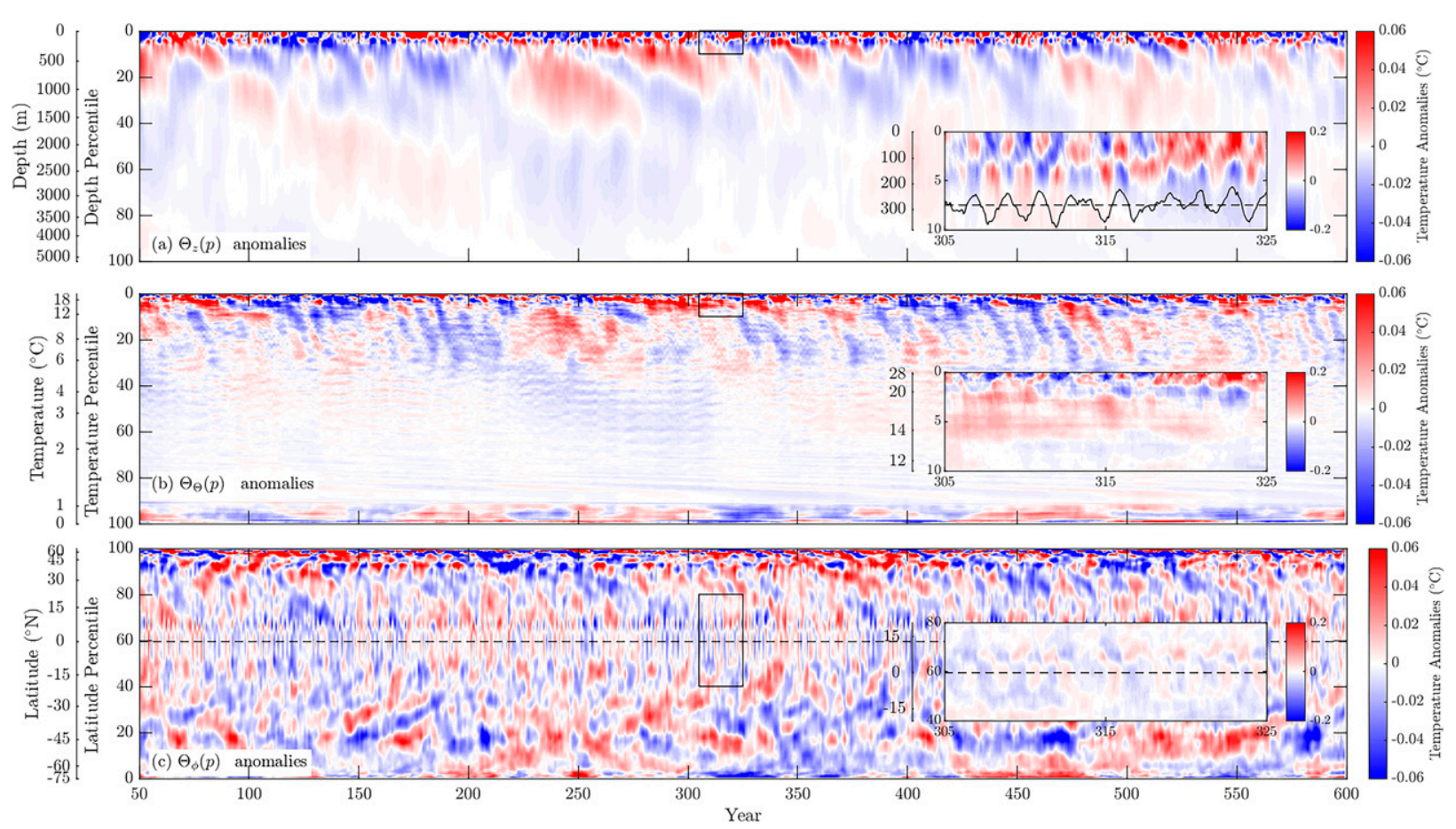

FIG. 4. Annual-average temperature anomalies from the ACCESS-CM2 PI control simulation in (a) depth-, (b) temperature-, and (c) latitude-percentile coordinates. The insets are monthly anomalies (rather than annual averages) over a short 20-yr period marked with black boxes (note the different color scale in the insets). The black solid line plotted in the inset in (a) is the Niño-3.4 index (with values above the dashed black line corresponding to El Niño events). The dashed black line in (c) marks the equator.

\section{a. Interannual variability: ENSO}

When applied to interannual frequency variability our framework reveals the diabatic and adiabatic signatures of ENSO variability. The clear interannual dipole signature with alternating anomalies in the upper $\sim 110 \mathrm{~m}$ and between 110 and $220 \mathrm{~m}$ (inset in Fig. 4a) is associated with changes in the slope of the equatorial Pacific thermocline during El Niño and La Niña events (Roemmich and Gilson 2011; Cheng et al. 2019). This dipole is synchronized with the Niño-3.4 index, and has a strong lag-0 relationship with global mean SST (the surface value of Fig. 4a, Johnson and Birnbaum 2017). A lagregression of the temperature variability in each coordinate onto the Niño-3.4 index illustrates this dipole structure (Fig. 6a). The tilting of the equatorial thermocline is largely thought to be an adiabatic response to changes in the strength of the trade winds, which also drive a phase-shifted adiabatic equatorial recharge/discharge of heat content with positive equatorial heat content anomalies leading up to the peak of an El Niño (Fig. 6c; Cane and Zebiak 1985; Jin 1997; Cheng et al. 2019).

If the OHC redistribution toward the surface (Fig. 6a) and toward higher latitudes (Fig. 6c) during ENSO was purely adiabatic then there would be no signature in the diabatic temperature coordinate (Figs. $4 \mathrm{~b}$ and $6 \mathrm{~b}$ ). This is not the case. While the ENSO-regressed anomalies are reduced overall in temperature compared to depth coordinates (cf. Figs. 6a,b), there is still a clear diabatic ENSO signature. This signature is restricted to a narrower range of percentiles $\left(>16^{\circ} \mathrm{C}, p<4 \%\right)$ compared to depth, but otherwise shows a similar dipole pattern with slightly different phasing. At the warmest temperatures $\left(>25^{\circ} \mathrm{C}, p<1 \%\right)$ the warm anomaly during El Niño (indicating an expansion of the volume of warm water) is stronger in the temperature coordinate than in depth, because these warm waters are isolated largely to the tropical Pacific where ENSO has its largest impacts. In contrast, the depthcoordinate average includes mid and high-latitude regions where ENSO impacts are reduced. In the colder pole of the dipole $\left(15^{\circ}-24^{\circ} \mathrm{C}, 1 \%<p<5 \%\right.$ in Fig. $\left.6 \mathrm{~b}\right)$ the temperaturecoordinate anomalies are weaker than their depth-coordinate counterpart. The warm anomalies that dominate between 1.5 years and 3 months prior to an El Niño are phase shifted earlier than the equatorial heat content anomalies associated with meridional recharge and discharge (cf. Figs. 6b,c). This is consistent with Huguenin et al. (2020) who emphasized that the diabatic discharge of warm water across the $20^{\circ} \mathrm{C}$ isotherm led adiabatic changes in equatorial warmwater volume due to the meridional discharge of heat by several months.

Previous work has emphasized the impact of diabatic heat exchange between the atmosphere and ocean during ENSO events (Mayer et al. 2014, 2016; Cheng et al. 2019; Trenberth 2020). However, diabatic exchange can also include internal ocean heat exchange between temperature layers associated with turbulent mixing. To better understand the drivers of the ENSO-regressed temperature anomalies we examine ENSO-regressed heat budget tendencies for both depth- and 

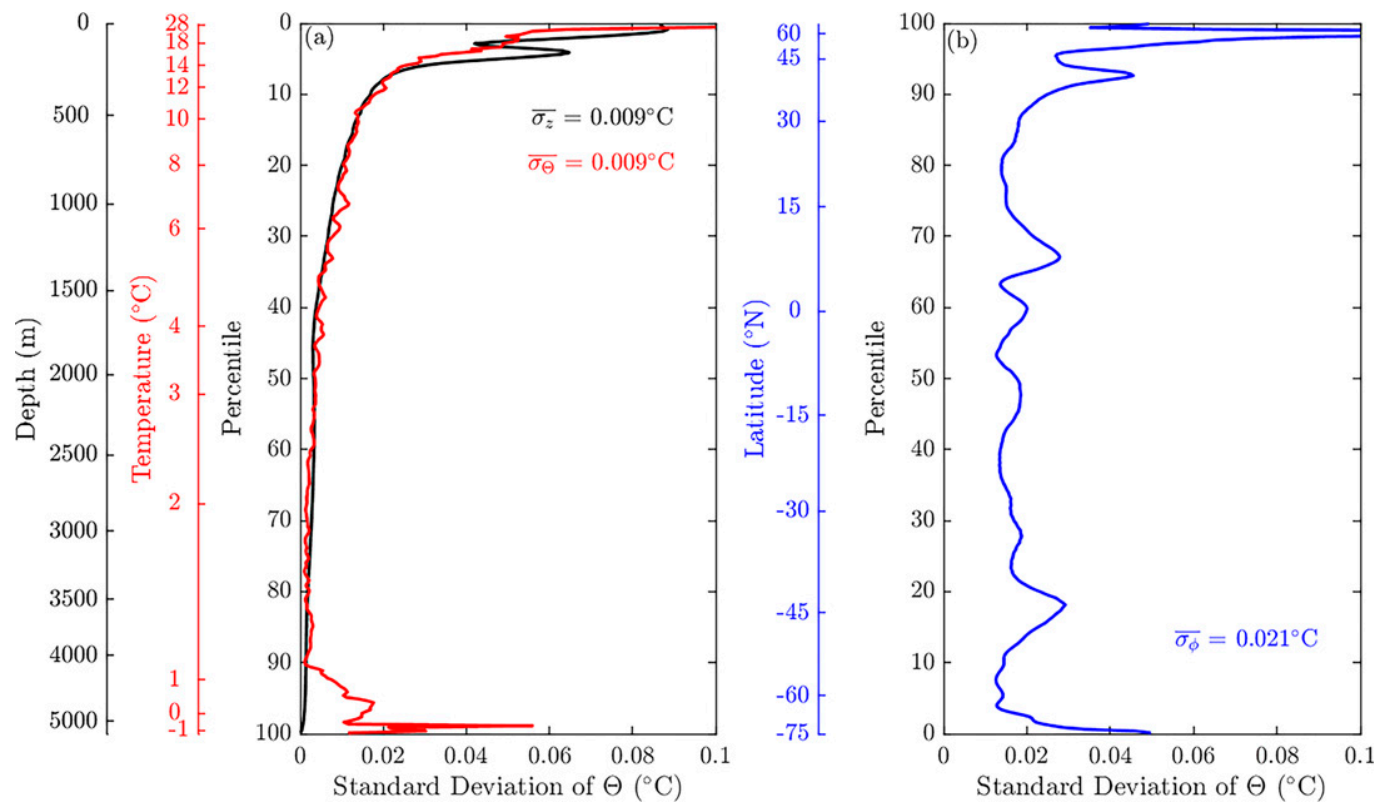

FIG. 5. The standard deviation of temperature anomalies in (a) depth (black), temperature (red), and (b) latitude percentiles. The average over all percentiles is indicated inside the panel.

temperature-percentile coordinates (Fig. 7). As expected, the depth-coordinate variability associated with ENSO is driven largely by adiabatic vertical advection (Fig. 7c). Changes in vertical heat transport associated with vertical mixing make a small contribution (Fig. 7b). Reduced mixing in the upper $\sim 1.5 \%(\sim 50 \mathrm{~m})$ leading into and during the peak of El Niño leads to surface warming and subsurface cooling (red and blue patches in Fig. $7 \mathrm{~b}$ at lags from -0.5 to 0 ), while mixing penetrates to greater depths in the eastern Pacific during El Niño when the thermocline is deeper (leading to some deeper warming below $1.5 \%$, Fig. $7 \mathrm{~b}$ at lags $0-0.5)$. Surface forcing contributes only in the very shallow shortwave absorption layer (Fig. 7a). As for depth coordinates, the latitude-coordinate Niño-3.4-regressed temperature tendency is driven almost exclusively by advection, associated with meridional recharge and discharge and changes in the subtropical cells (Cane and Zebiak 1985; McGregor et al. 2014; Hieronymus and Nycander $2020)$, with surface forcing making a small $(<10 \%)$ contribution (not shown).

In the temperature-coordinate adiabatic processes are filtered out by construction, leaving only surface forcing and mixing terms (Figs. 7d,e,f). Surface forcing is the largest term (note the saturated color scale in Fig. 7d). At the peak of El Niño the ocean loses heat to the atmosphere over the range of temperature below $26^{\circ} \mathrm{C}(p>0.625 \%)$ due to warm SST anomalies in the eastern Pacific (Cheng et al. 2019; Trenberth 2020). There is a slight gain of heat by the warmest waters from the atmosphere $\left(>26^{\circ} \mathrm{C}, p<0.625 \%\right)$, likely associated with the movement of warm pool waters into the eastern Pacific where heat gain is more prevalent in the mean. However, both vertical and numerical mixing also contribute (Figs. 7e,f). The vertical and numerical mixing patterns are similar and reflect a weakening of mixing during the peak of El Niño (Warner and Moum 2019; Huguenin et al. 2020; Deppenmeier et al. 2021) over the temperature range between $26^{\circ}$ and $17^{\circ} \mathrm{C}(0.625 \%<p<3.25 \%)$, with some strengthening in mixing-driven tendencies at warmer temperatures (associated with the movement of these waters into the eastern Pacific where mixing is more prevalent in the mean).

\section{b. Low-frequency variability}

Below the top $250 \mathrm{~m}$, at temperatures below $20^{\circ} \mathrm{C}$ and for latitudes outside of the equatorial band, lower frequency decadal-to-centennial variability dominates (Fig. 4).

\section{1) MID-DEPTH/MID-TEMPERATURE VARIABILITY}

There is a distinct centennial signal that shows evidence of downward propagation in depth coordinates (e.g., downwardpropagating warm and cold phases between years 80 and $250,10 \%<p<80 \%$ in Fig. 4a). A similar signal appears in temperature coordinates, with a correspondence in phase (Fig. 4b). Time series of 10-yr low-pass temperature anomalies averaged over the $10 \%<p<30 \%$ range in depth (between 380 and $1200 \mathrm{~m}$, black line in Fig. 8a) and temperature (between $6^{\circ}$ and $12^{\circ} \mathrm{C}$, red line in Fig. 8a) are correlated with a Pearson's correlation coefficient of 0.66 . Regression of the $\Theta_{z}(10 \%<p<30 \%, t)$ time series onto zonally summed heat content anomalies in the depth-latitude plane indicates that this variability is associated with a pattern of warming in the upper ocean (above $2000 \mathrm{~m}$ ) and cooling in the deep ocean (between 2000 and $4000 \mathrm{~m}$ ), with the strongest warming focused in the midlatitudes between $40^{\circ}$ and $20^{\circ}$ latitude in both hemispheres (Fig. $8 \mathrm{~b}$, also see Fig. 4c). These warming patterns are in the zonal- 

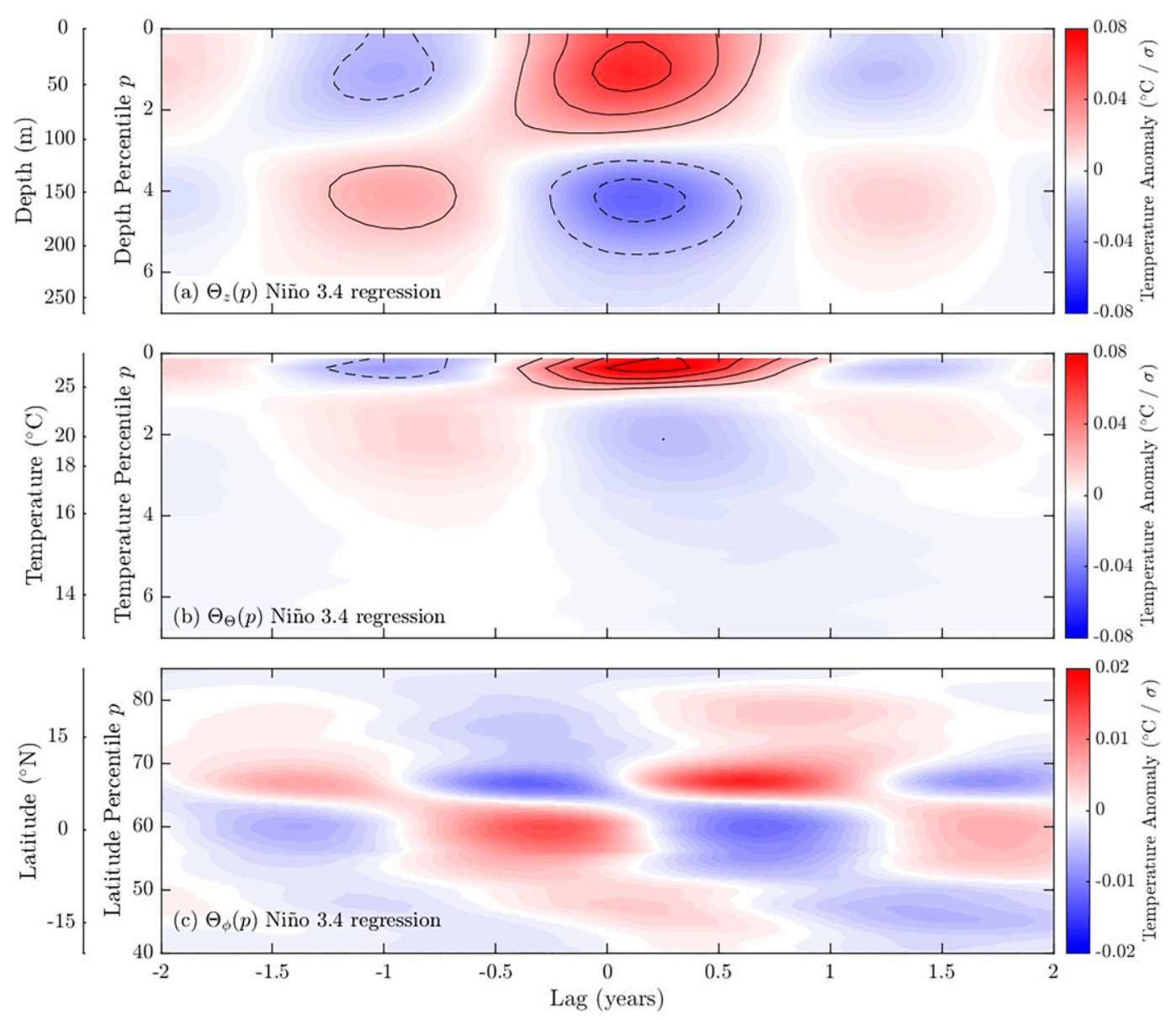

FIG. 6. Lag regression of the temperature variability in (a) depth-, (b) temperature-, and (c) latitude-percentile coordinates onto the Niño-3.4 index (normalized by its standard deviation of $\sigma=0.85^{\circ} \mathrm{C}$ ) from the ACCESS-CM2 PI control simulation. Positive (solid) and negative (dashed) contours with $0.02^{\circ} \mathrm{C}$ spacing have been added to facilitate comparison. Note the different color scale used in (c).

mean temperature range of $6^{\circ}-14^{\circ} \mathrm{C}$, consistent with the temperature-percentile range at which decadal variability is most prominent.

What is driving this multidecadal variability in subsurface temperatures? While a full investigation is outside of the scope of this article, a good candidate is multidecadal variability in the global meridional overturning circulation (GMOC), well known in both observations and models (e.g., Dong and Sutton 2005; Park and Latif 2008; Delworth and Zeng 2012; Menary et al. 2012; Oldenburg et al. 2021). Lag regressions of the $\Theta_{z}(10 \%<p<30 \%, t)$ time series onto the global zonal mean MOC in $y, z$ coordinates (we favor a depth-space calculation over a density-coordinate MOC to avoid the complications arising from the inflation and deflation of density layers) illustrate a relationship between the two. For negative lags up to 50 years leading up to the peak of the temperature anomaly the interhemispheric GMOC cell is weak (illustrated at lag -40 years in Fig. 8c). For positive lags up to 50 years after the peak of the temperature anomaly the interhemispheric GMOC cell is generally strong (illustrated at lag +40 years in
Fig. 8d). The interhemispheric overturning cell is thermally indirect, driving a downward advective heat transport that is thought to dominate the mean vertical advective heat transport at mid-depths (Zika et al. 2013; Savita et al. 2021). Thus, a weakening in the interhemispheric overturning cell (with anomalies peaked in the depth range of 1000-1500 m, Figs. $8 \mathrm{c}, \mathrm{d})$, would be expected to lead to an upward anomalous heat transport consistent with the formation of the observed decadal-to-centennial pattern of warm anomalies in the upper $1000 \mathrm{~m}$ and cold anomalies below (Fig. 8b). Analysis of lag correlations of the $\Theta_{z}(10 \%<p<30 \%, t)$ time series with the heat budget shows that advection is the dominant term responsible for the positive tendency in heat content above $1500 \mathrm{~m}$ leading to the warm anomalies in Fig. 8b (not shown). Of course, advection cannot be responsible for the temperature anomalies in temperature coordinates, which appear to be closely related to the depth-coordinate anomalies (Fig. 8a). Instead, these appear to be driven by anomalies in surface forcing, likely related to the coupled surface variability responsible for the variations in the GMOC itself. 

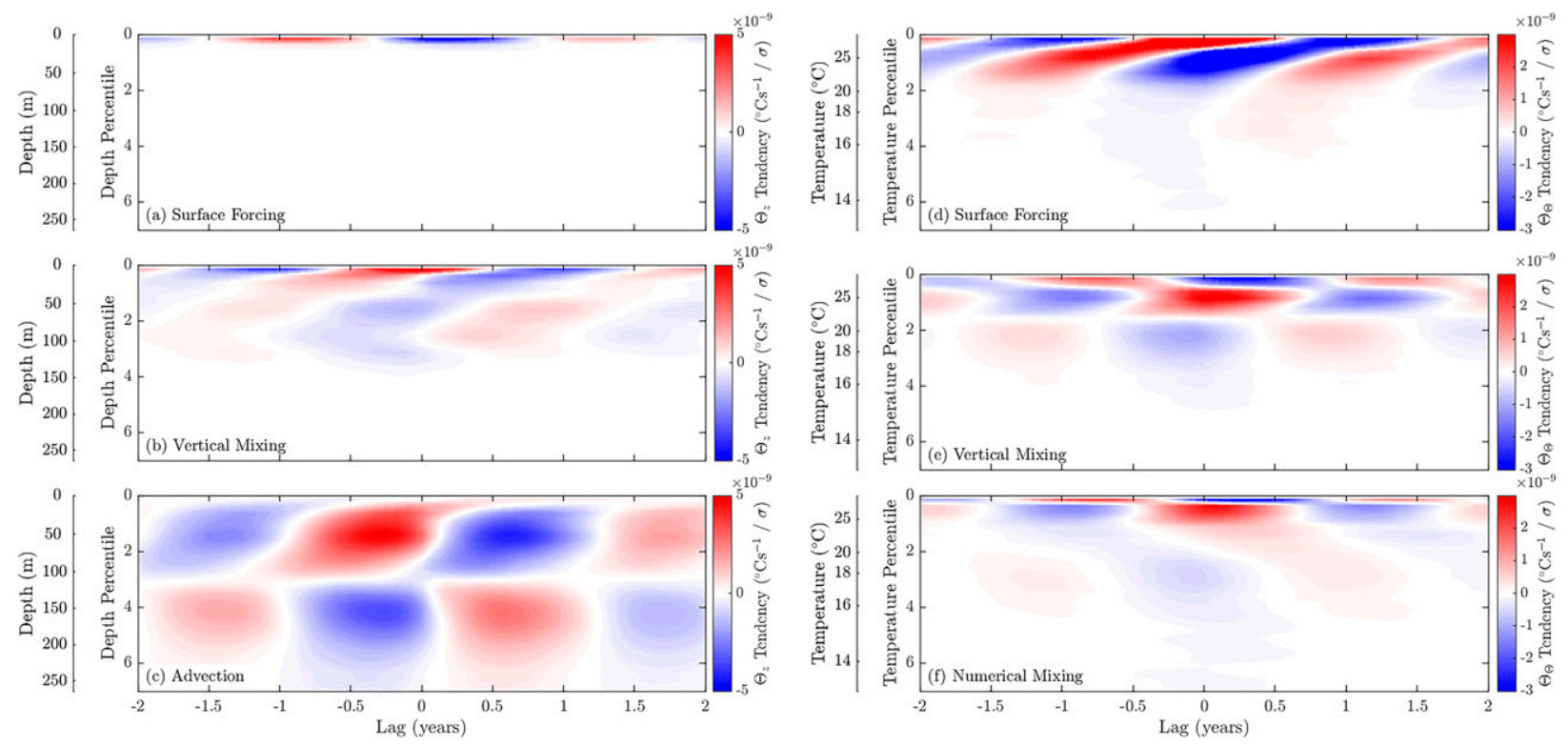

FIG. 7. Regressions of temperature budget tendency terms in (a)-(c) depth- and (d)-(f) temperature-percentile coordinates onto the Niño-3.4 index over the top $7 \%$ (maximum depth of $\sim 260 \mathrm{~m}$ or minimum temperature of $\sim 13^{\circ} \mathrm{C}$ ). The budget terms shown are temperature tendencies within each volume percentile, e.g., (a) shows the quantity $100\left(\rho_{0} c_{p} V\right)^{-1} \partial \mathcal{F}_{z} / \partial p$ regressed onto Niño-3.4, where $\mathcal{F}_{z}$ is the surface forcing term in the depth-percentile heat budget in Eq. (7). Note the color-scale difference between the left and right columns. The total tendency, matching the time derivative of Figs. $6 \mathrm{a}$ and $6 \mathrm{~b}$, respectively, is given by the sum of these processes plus the contribution of neutral mixing, which is negligible for the Niño-3.4 regression in all coordinates (not shown).

\section{2) COLD TEMPERATURE VARIABILITY}

An advantage of the temperature coordinate compared to the depth coordinate is that it isolates variability at cold temperatures in the high-latitude surface waters (Sohail et al. 2021). These cold temperatures also contain a multidecadal to centennial signal $\left(\$ 1^{\circ} \mathrm{C}, 90 \%<p<100 \%\right.$ in Figs. $4 \mathrm{~b}$ and $9 \mathrm{a}$ ), characterized by a distinctive pattern of warming in the Southern Ocean south of $55^{\circ} \mathrm{S}$ and between 4000 - and 500-m depth when regressed onto zonally summed heat anomalies (Fig. 9b, also compare to high southern latitude variability in Fig. 4c). A similar regression onto the GMOC illustrates an association of this high-latitude warming with a weakening in the bottom water cell south of $60^{\circ} \mathrm{S}$ in the Southern Ocean, as well as a weakening and shoaling of the interhemispheric deep water cell (Fig. 9c). Indeed, there is a maximum positive lag correlation of 0.52 at a lag of -49 years between the cold time series (Fig. 9a) and the mid-depth time series (black line in Fig. 8a), which is not surprising given the similarity between Figs. $8 \mathrm{c}$ and 9c. Thus, the multidecadal variability at cold temperatures appears to be linked to variations in the GMOC and the associated surface heat flux anomalies over the high-latitude Southern Ocean.

\section{3) HIGH NORTHERN LATITUDE VARIABILITY}

Finally, there is also evidence of strong variability at far northern latitudes (Fig. 4c and 5b). Time series of temperature anomalies north of $45^{\circ} \mathrm{N}(95 \%<p<100 \%$, Fig. 10a) show strong variability (note the larger temperature scale in Fig. 10a compared to Figs. 8a and 9a) at time scales around
10 years (confirmed with spectral analysis in the next section), correlated with coherent warm anomalies throughout the upper 2000-3000 $\mathrm{m}$ at similar latitudes (Fig. 10b). This decadal signal likely represents local variability in the meridional heat transport associated with the Atlantic MOC, with positive GMOC anomalies in the high northern latitudes dominating 5 years prior to the warm peak (Fig. 10c). This signal does not appear to have a strong connection with the variability at cold temperatures (e.g., Fig. 9) or with the middepth and temperature variability (Fig. 8) as the time scale is shorter and does not project onto globally averaged depth or temperature coordinates due to compensation by cooling in the midlatitudes (Fig. 10b).

\section{c. Spectral analysis}

A more quantitative summary comparison of temperature variability and its drivers across different frequencies can be made using spectral analysis. We focus on spectra averaged across all percentiles, providing a fair comparison between the three coordinates (Fig. 11a). However, for temperatureand depth-percentile coordinates we note that the spectra are dominated by variability in the upper $10 \%$. At interannual frequencies variability is dominated by an ENSO peak at 2-3yr periods (ACCESS-CM2 has a more biennial ENSO than observations suggest, Bi et al. 2020). At these frequencies variability is stronger in depth and latitude percentiles than in temperature percentiles consistent with the results discussed in section 4a. Averaged over the interannual frequency band between 1 and 5 years the total variance in the temperature coordinate is $55 \%$ of that in depth (see Table 1 ). However, at 

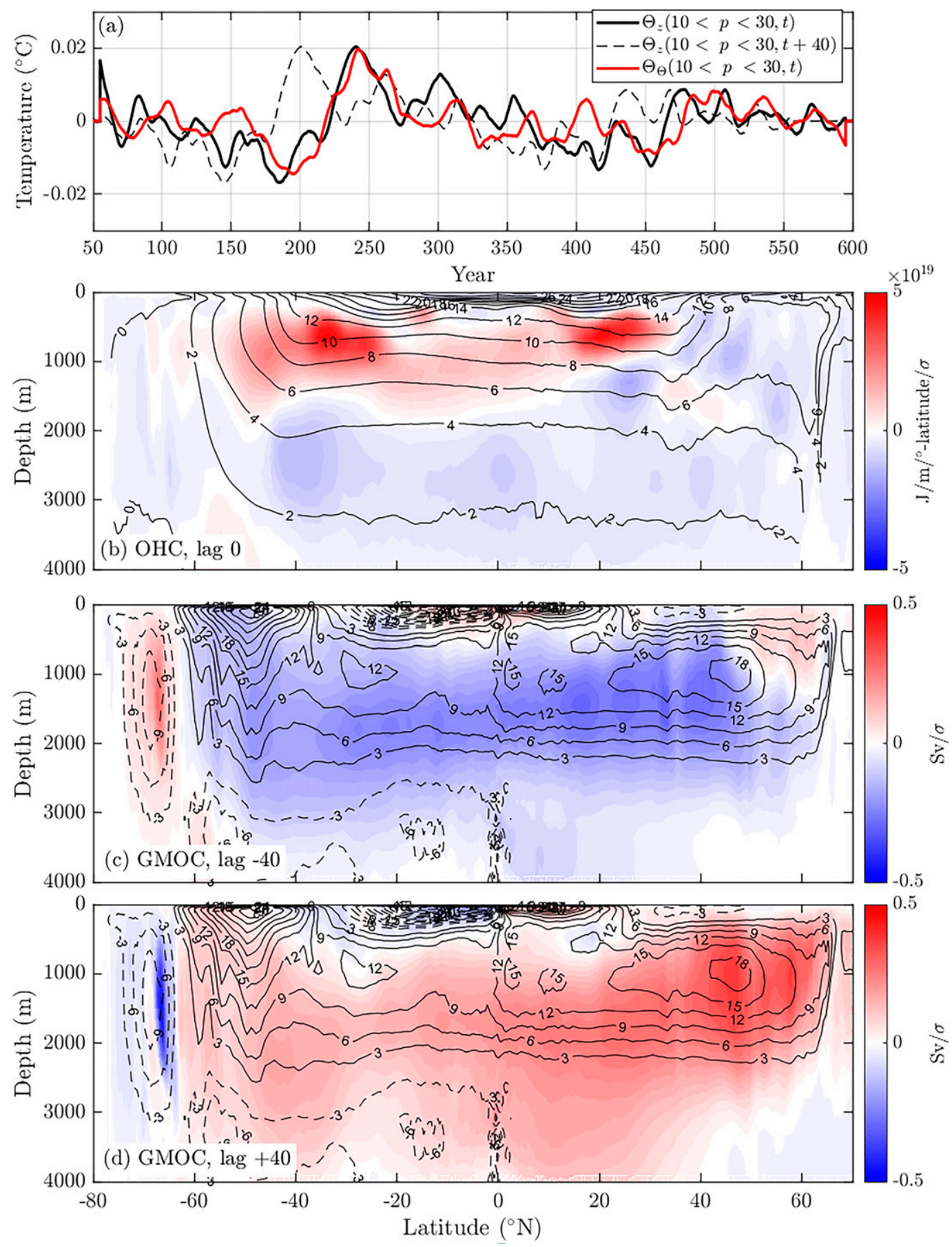

FIG. 8. (a) Time series of 10 -yr low-pass-filtered temperature anomalies $\left({ }^{\circ} \mathrm{C}\right)$ averaged between $10 \%$ and $30 \%$ in depth percentiles (black, corresponding to depths between 380 and $1200 \mathrm{~m}$ ) and temperature percentiles (red, corresponding to temperatures between $6^{\circ}$ and $\left.12^{\circ} \mathrm{C}\right)$. Also shown is the $\Theta_{z}(10 \%<p<30 \%, t)$ time series lagged forward by 40 years (thin black dashed line). Regressions of the $\Theta_{z}(10 \%<p<30 \%, t)$ time series [black line in (a)] onto (b) zonally summed heat content anomalies $\left(\mathrm{J} \mathrm{m}^{-1}\right.$ per degree latitude per standard deviation) at zero lag and anomalies in the GMOC [Sv $\left(1 \mathrm{~Sv} \equiv 10^{6} \mathrm{~m}^{3} \mathrm{~s}^{-1}\right)$ per standard deviation] at (c) -40 -yr lag [dashed black line in (a)] and (d) +40 -yr lag. Time- and zonal-mean isotherms are illustrated by contours in (b). The time-mean GMOC is contoured in (c) and (d), with solid (dashed) contours indicating clockwise (anticlockwise) circulation. 

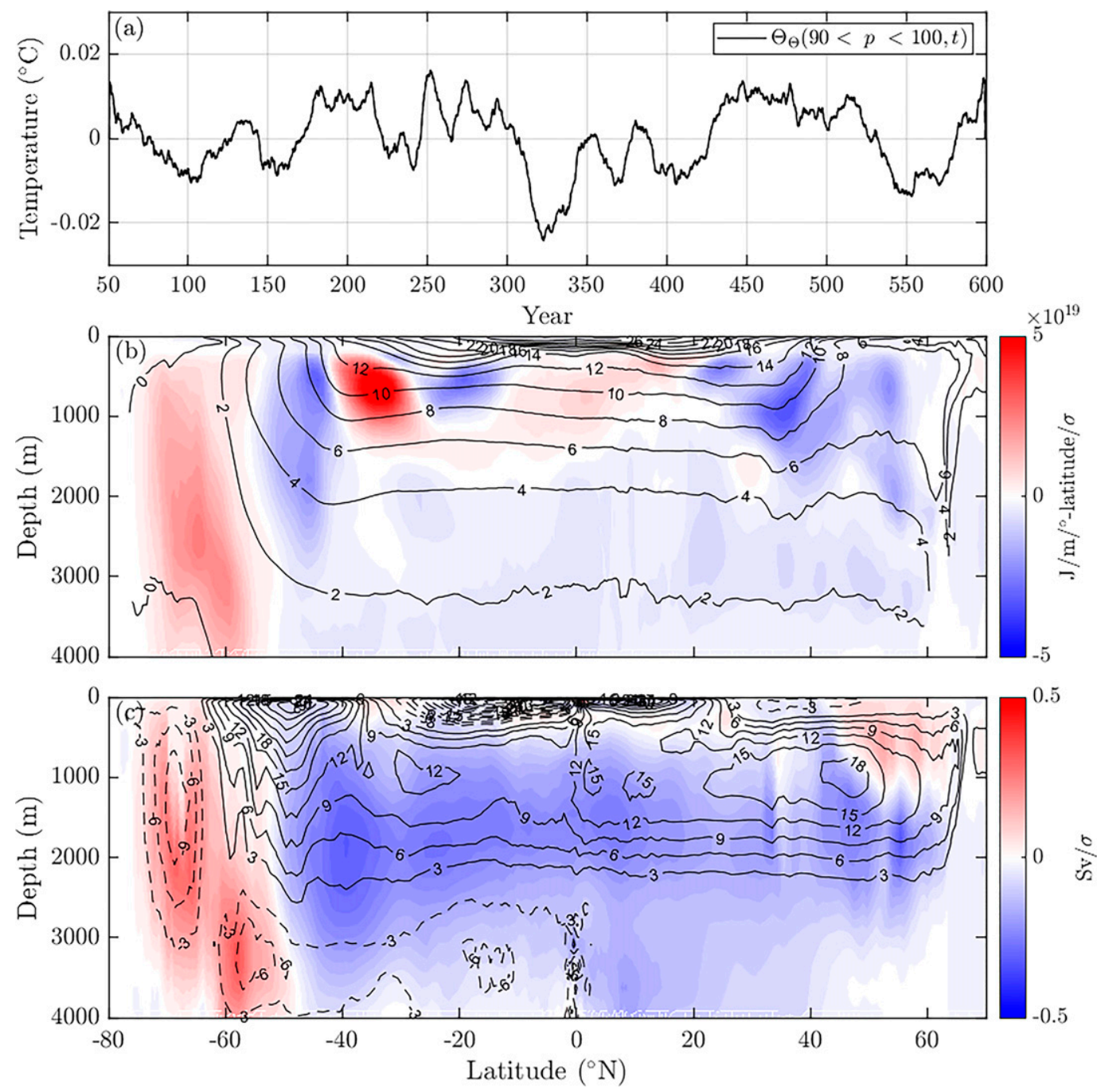

FIG. 9. (a) Time series of 1-yr low-pass-filtered temperature anomalies $\left({ }^{\circ} \mathrm{C}\right)$ averaged over the cold temperaturepercentile range of $90 \%<p<100 \%\left(\leqslant 1^{\circ} \mathrm{C}\right)$ from ACCESS-CM2. Zero-lag regression pattern of $\Theta_{\Theta}(90 \%<p<$ $100 \%, t)$ time series [black line in (a)] onto (b) zonally summed heat content anomalies $\left(\mathrm{J} \mathrm{m}^{-1}\right.$ per standard deviation) and (c) anomalies in the GMOC (Sv per standard deviation). Time- and zonal-mean isotherms are illustrated by contours in (b). The time-mean GMOC is contoured in (c) and (d), with solid (dashed) contours indicating clockwise (anticlockwise) circulation.

slower decadal and centennial frequencies variability in the temperature coordinate is comparable or larger than in the depth coordinate (cf. red and black lines in Fig. 11a). Averaged over the frequency band between 5 and 100 years the total variance in the temperature coordinate is $20 \%$ larger than in depth (Table 1).

Spectra of the heat budget terms illustrate the impact of adiabatic and diabatic processes across frequency (Figs. $11 b, c, d)$. Variability in temperature coordinates is dominated by surface forcing at all frequencies (black line in Fig. 11b), consistent with previous studies (Toole et al. 2004; Palmer and Haines 2009; Sohail et al. 2021). In contrast, advection is the largest term in depth coordinates (blue line in Fig. 11c) and dominates the variability across all frequencies in latitude coordinates (blue line in Fig. 11d, consistent with Roberts et al. 2017). At interannual frequencies these results are consistent with the ENSO analysis in the previous section; In depth and latitude coordinates the total tendency closely matches the advection term, while in temperature coordinates surface forcing dominates. However, in temperature coordinates vertical and numerical mixing appear to compensate for a small portion of the surface-forcing driven variability (i.e., the variance in the total tendency is less than that arising from surface forcing alone, compare magenta and black lines in Fig. 11b). This slight compensation (also evident comparing Figs. 7d,e,f at lag-0) illustrates ENSO-related variations in the near-surface mean state balance between surface fluxdriven warming and mixing-driven cooling in the eastern 

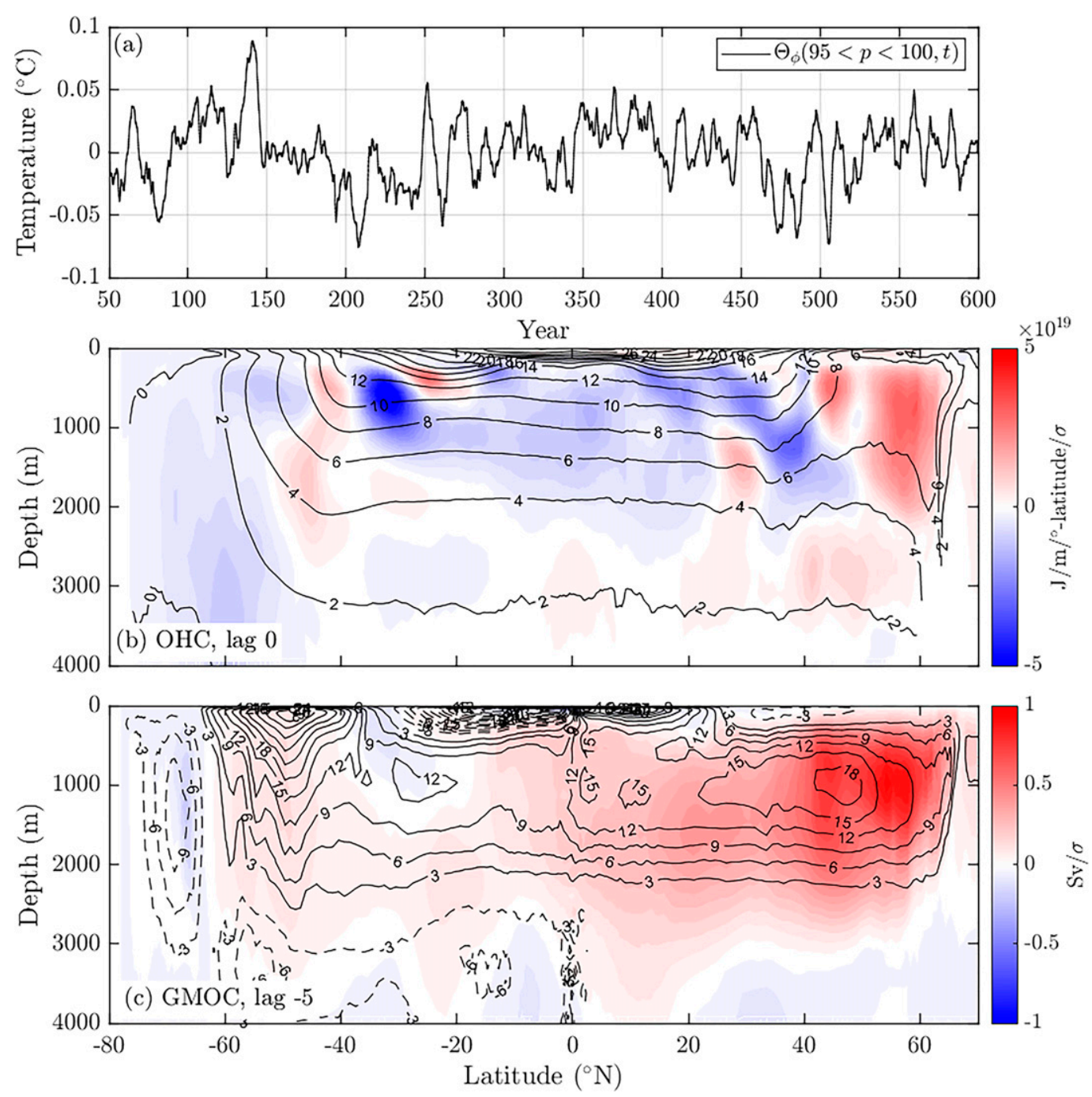

FIG. 10. (a) Time series of 1-yr low-pass-filtered temperature anomalies $\left({ }^{\circ} \mathrm{C}\right)$ averaged over latitudes north of $\sim 45^{\circ} \mathrm{N}$ (latitude percentiles between $95 \%$ and $100 \%$ ). Regressions of the $\Theta_{\phi}(95 \%<p<100 \%, t)$ time series (a) onto (b) zonally summed heat content anomalies $\left(\mathrm{J} \mathrm{m}^{-1}\right.$ per degree latitude per standard deviation) at zero lag and (c) anomalies in the GMOC (Sv per standard deviation) at -5-yr lag. Time- and zonal-mean isotherms are illustrated by contours in (b). The time-mean GMOC is contoured in (c), with solid (dashed) contours indicating clockwise (anticlockwise) circulation.

equatorial Pacific (Huguenin et al. 2020; Deppenmeier et al. 2021).

At decadal and slower frequencies the dominant budget variability balance changes. In particular, in all three coordinates the total tendency term tends to reduce at longer time scales (magenta lines in Figs. 11b,c,d), indicating a tendency for compensation between process perturbations. In temperature-percentile coordinates this compensation is between surface forcing, vertical mixing, and numerical mixing, reflecting the mean state balance between these processes (e.g., Fig. 3a). In depth-percentile coordinates the dominant low-frequency balance is between advection and vertical mixing (blue and green lines in Fig. 11c). Spectra of the sum of advection and vertical mixing decays below either of the individual terms at periods longer than $\sim 30$ years (not shown). This advectionvertical mixing balance at low frequencies is dominant mainly in the upper $150 \mathrm{~m},(p>4 \%$, not shown $)$ and thus is not reflective of a deep ocean vertical advective-diffusive balance (Munk 1966), or of the interior ocean GMOC-related variability discussed in section $4 \mathrm{~b}$. This advective-vertical mixing balance highlights the importance of diabatic processes for decadal variability of vertical heat transport in the surface ocean. In latitude coordinates there is also evidence of cancellation at low frequencies between advection and surface forcing (Fig. 11d), suggesting that low-frequency ocean heat transport variability can be partially compensated by heat loss to the atmosphere.

Finally, we note that while the decadal-to-centennial variability in the latitude-percentile coordinate appears much 

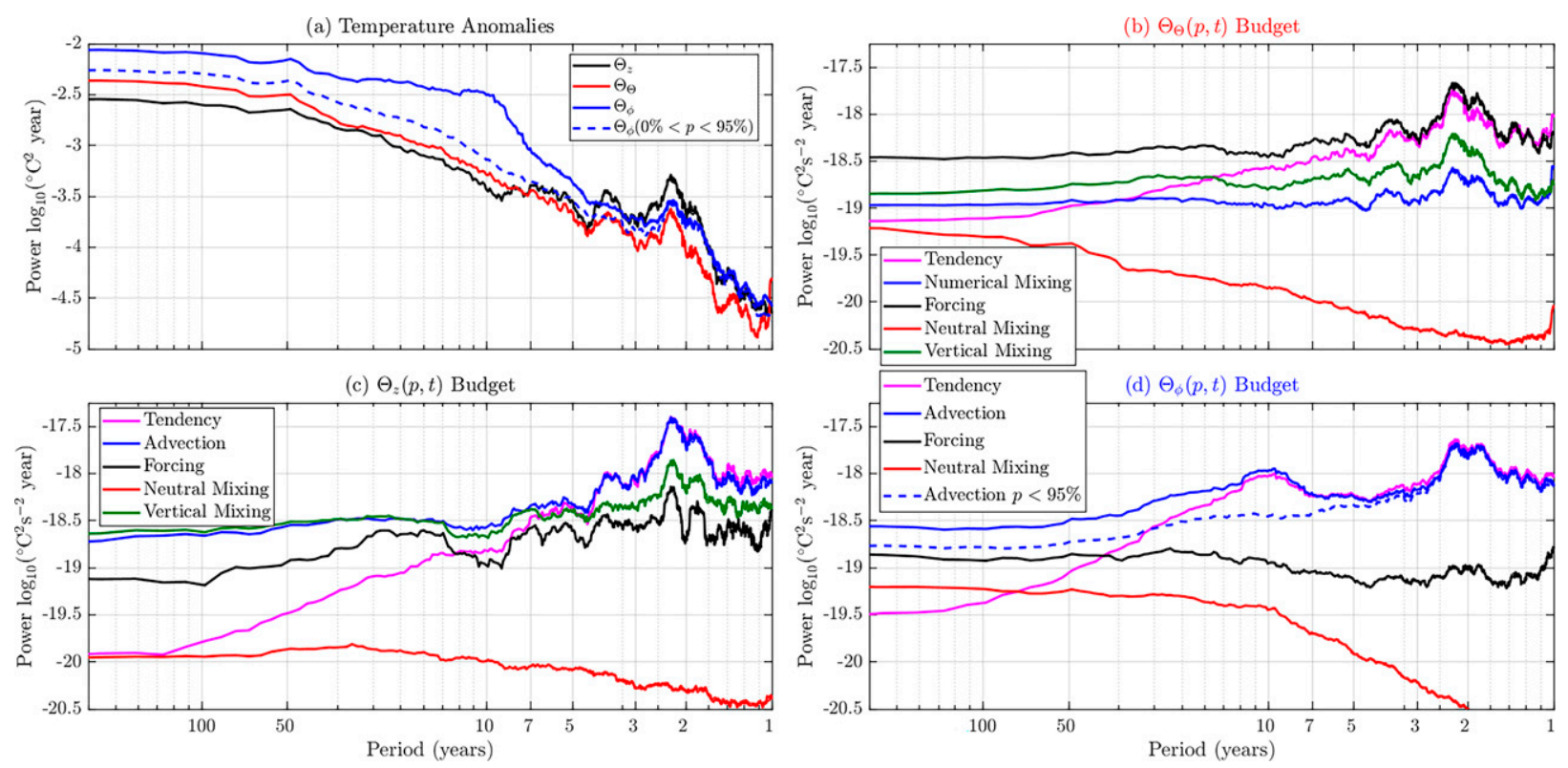

FIG. 11. (a) Power spectra of temperature variability in each percentile coordinate averaged across all percentiles. Contributions of budget terms to the spectra of temperature tendencies in (b) depth-, (c) temperature-, and (d) latitude-percentile coordinates, averaged across all percentiles. Power spectra are calculated using monthly data and Thompson's multitaper method with 19 Slepian tapers. The dashed blue lines indicate results from the latitude-percentile analysis excluding the high northern latitudes (north of $45^{\circ} \mathrm{N}, p=95 \%$ ).

larger than that in temperature and depth coordinates (cf. blue, red and black lines in Fig. 11a), a significant fraction of this signal is associated with the strong decadal signal in the high-latitude Northern Hemisphere identified in section $4 \mathrm{~b}$ (e.g., Fig. 10). Excluding the ocean north of $45^{\circ} \mathrm{N}(p>95 \%)$ removes the peak in advective meridional heat transport convergence at 7-13-yr periods and leaves a weaker temperature variability signal at decadal-to-centennial frequencies (cf. blue solid and dashed lines in Figs. 11d,a).

\section{Discussion: Estimating global OHC}

In this final section we discuss the impact of internal variability within each coordinate on estimates of global $\mathrm{OHC}$ variability and trends. Palmer et al. (2007, 2009) compared observed and modeled ocean temperature variability and trends averaged above the $14^{\circ} \mathrm{C}$ isotherm and the $220-\mathrm{m}$ depth surface, respectively (corresponding to a volume percentile of about $p=6 \%$ ), showing that both interannual and decadal time-scale variability was reduced by $30 \%-40 \%$ in the

TABLE 1. A summary of the temperature variability in depth-, latitude-, and temperature-percentile coordinates separated into interannual (faster than 5-yr period) and decadal to centennial (slower than 5-yr period) time scales. All entries have the units of $10^{-4}{ }^{\circ} \mathrm{C}^{2}$.

\begin{tabular}{lccc}
\hline \hline \multicolumn{1}{c}{ Frequency } & $\begin{array}{c}\text { Depth } \\
\text { percentile } \Theta_{z}\end{array}$ & $\begin{array}{c}\text { Temperature } \\
\text { percentile } \Theta_{\Theta}\end{array}$ & $\begin{array}{c}\text { Latitude } \\
\text { percentile } \Theta_{\phi}\end{array}$ \\
\hline Interannual & 1.17 & 0.64 & 1.03 \\
Decadal/centennial & 1.34 & 1.61 & 5.12 \\
\hline
\end{tabular}

temperature-coordinate analysis (see Table 1 in Palmer et al. 2007) and that long-term warming trends was more robustly identifiable. Here we assess the full range of possible isobar/ isotherm choices, using the rigorous volume percentile approach which avoids the potential ambuiguity associated with volume variability (see appendix A). For this purpose, we consider variability in the cumulative $\mathrm{OHC}$ integrated from low to high percentile [i.e., $\mathcal{H}$ in Eq. (5), where the integral is starting at the surface, at warm temperatures or at the South Pole, respectively].

In depth and temperature coordinates, the variability of cumulative $\mathrm{OHC}$ builds up strongly through the top $10 \%$, reflecting the dominance of surface and warm temperature variability (black and red solid lines in Fig. 12a). The peak at $p \sim 4 \%$ in depth coordinates is associated with the node in ENSO-related temperature variability (e.g., black line in Fig. 5a) that is largely filtered out in the temperature coordinate (but is also evident near the equator, blue solid line in Fig. 12d). At interannual frequencies the ENSO-related peak is the only amplitude difference between depth- and temperature-percentile coordinates (cf. dotted red and black lines in Fig. 12a). At the $14^{\circ} \mathrm{C}$ isotherm and $220-\mathrm{m}$ depth surfaces $(p=6 \%$ ) we find a reduction in interannual variability of $\sim 25 \%$, in decadal low-frequency variability of $\sim 14 \%$ and in total variability of about $18 \%$ in temperature- compared to depth-percentile coordinates. These reductions are somewhat weaker than those reported by Palmer et al. (2007) from observations (of $30 \%-40 \%$, see their Table 1) a difference which either stems from model-observation variability bias or suggests that some of the advantage of the temperaturecoordinate analysis may stem from a reduction in the impact 

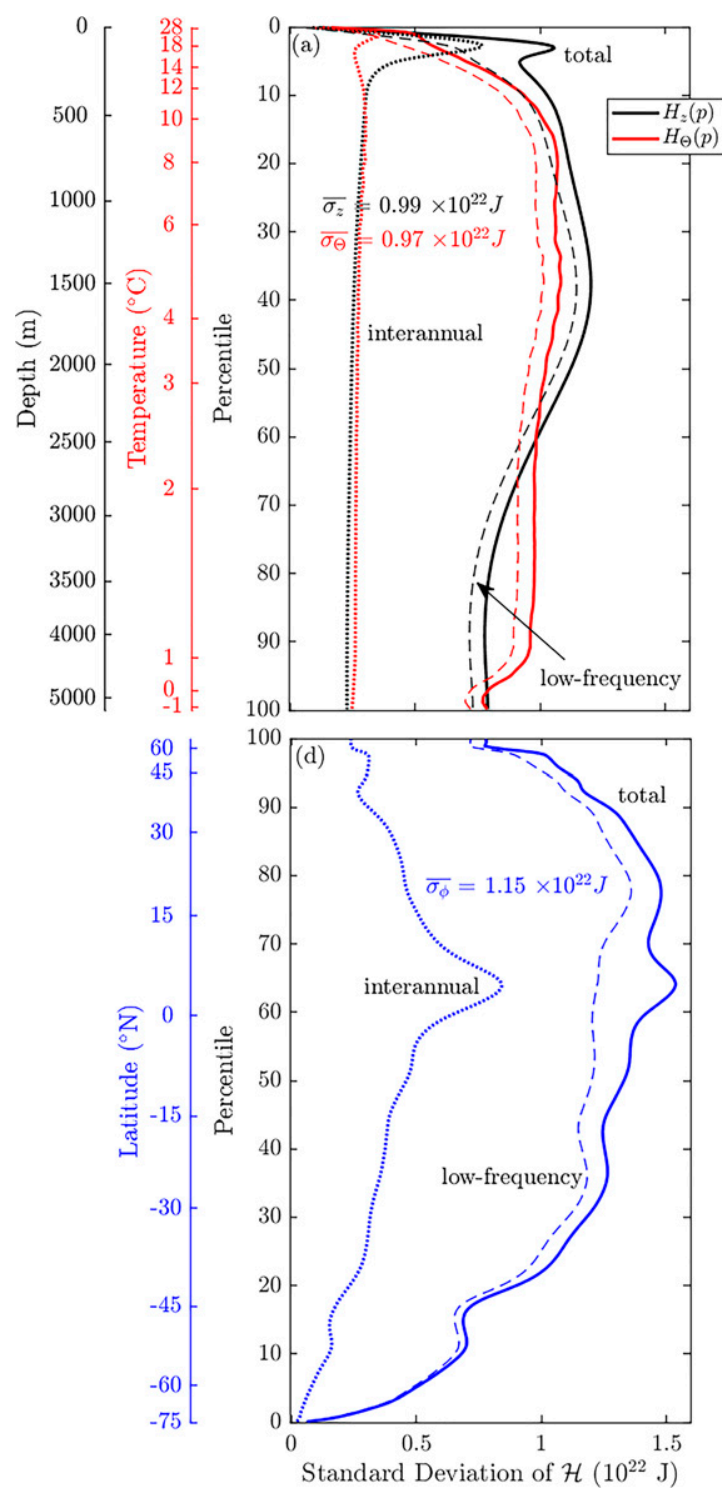
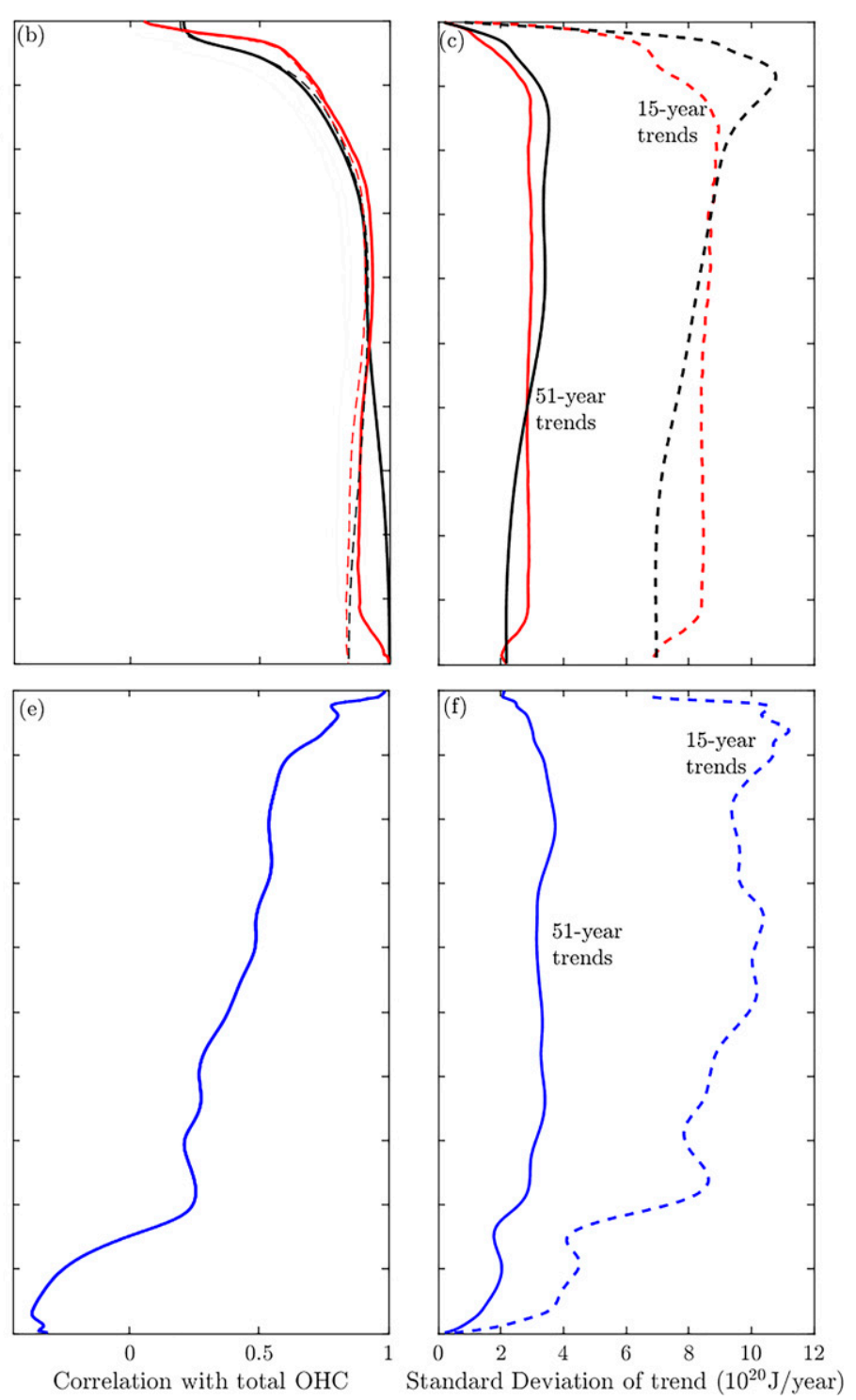

FIG. 12. (a),(d) The standard deviation of cumulative heat content anomalies $\mathcal{H}_{C}$ [Eq. (5)] in (a) depth (black) and temperature (red), and (d) latitude percentiles. The average over all percentiles is listed inside the panels. The solid line is the standard deviation of the total signal, while the dashed and dotted line represent the standard deviation of 5-yr low-passed (decadal to centennial) and high-passed (interannual) anomalies, respectively. (b),(e) The correlation of $\mathcal{H}_{C}$ with the total OHC $\left[\mathcal{H}_{C}(p=100 \%, t)\right]$. The dashed line shows the same calculation excluding the high-latitude regions poleward of $\pm 60^{\circ}$. (c),(f) The standard deviation of (solid lines) 15-yr and (dashed line) 51-yr trends of cumulative heat content anomalies in depth (black) and temperature (red) in (c), and latitude percentiles in (f).

of observational sparse sampling. In either case, our analysis suggests that a significant proportion of the reduction in variance of cumulative OHC in the Palmer et al. (2007) analysis stems from the filtering out of adiabatic variability in depth coordinates associated with ENSO, as discussed in section 4a.

Apart from the ENSO-related peak near $p \sim 4 \%$ in depth, the total variability in cumulative $\mathrm{OHC}$ is dominated by decadal to centennial frequencies slower than 5 years (cf. dashed and solid lines in Figs. 12a,d). Consequently, consistent with the results from previous sections we see only a small reduction of up to $10 \%$ in variability in the temperature coordinate compared to the depth coordinate down to $p \approx 60 \%$ (cf. black and red solid lines in Fig. 12a). Spectral analysis also indicates that variability in the cumulative $\mathrm{OHC}$ budgets are more similar between temperature- and depth-percentiles than in the temperature budgets examined in the previous section (Fig. 11). The cumulative $\mathrm{OHC}$ variability is dominated more by surface forcing in both depth and temperature percentiles than temperature anomalies at a given depth or temperature percentile (not shown).

At the maximum depth of XBT observations at $700 \mathrm{~m}(p \approx$ $18 \%$, corresponding to the $8.6^{\circ} \mathrm{C}$ isotherm) the reduction in 
total variability in the temperature coordinate compared to the depth coordinate is $\sim 4 \%$, while at the standard Argo float maximum depth of $2000 \mathrm{~m}$ ( $p \approx 50 \%$, corresponding to $3.2^{\circ} \mathrm{C}$ isotherm) the reduction is $\sim 9 \%$. Of course these comparisons are not strictly fair as the $8.6^{\circ}$ and $3.2^{\circ} \mathrm{C}$ isotherms descend to depths below the observed 700- and 2000-m levels, respectively. Nevertheless, the conclusion that the variability is slightly reduced in temperature coordinates compared to depth holds throughout the upper $2000 \mathrm{~m}$.

The small reduction in variability in the temperature coordinate compared to the depth coordinate through the range $5 \%-50 \%$ is reflected in a small increase in the correlation between the cumulative $\mathrm{OHC}$ at a given percentile and global OHC anomalies (cf. red and black solid lines in Fig. 12b). This suggests that temperature may be a slightly more robust coordinate if one is interested in a best estimate of the global OHC (the dominant energy reservoir in the Earth system on climate-relevant time scales) given a sparse observing system, although the differences are minor. This conclusion is little altered if the poorly observed polar regions beyond $\pm 60^{\circ}$ latitude (Trenberth et al. 2016) are excluded (dashed lines in Fig. 12b).

At larger percentiles, beyond $p=60 \%$, the variability in cumulative heat content in the depth-percentile coordinate becomes smaller than that in the temperature-percentile coordinate (cf. black and red lines in Fig. 12a) due largely to an anticorrelation between OHC above and below $2000 \mathrm{~m}$ consistent with the GMOC variability discussed in section $4 \mathrm{~b}$ (e.g., Fig. 8b, also see Palmer and McNeall 2014). Furthermore, there is a reduction in cumulative $\mathrm{OHC}$ in the temperature coordinate at the very cold temperatures, suggesting an anticorrelation between variability at cold (subpolar, $p>$ $90 \%$ ) temperatures with that at warm temperatures. Once again, this is consistent with the analysis in section $4 \mathrm{~b}$ where warm anomalies in the high-latitude Southern Ocean occurred in coincidence with cold anomalies at lower latitudes and warmer temperatures (Fig. 9b). This anticorrelation is also reflected in the negative correlation of $\mathrm{OHC}$ variability south of $45^{\circ} \mathrm{S}$ with the global OHC (Fig. 12e at $p<15 \%$ ). Furthermore, it implies that while the exclusion of the poorly observed polar regions does not overly impact the phasing of the variability of $\mathrm{OHC}$ (through the correlation, compare solid and dashed lines in Fig. 12b), it may increase its amplitude.

Finally, similar conclusions hold if we consider the magnitude of linear trends in heat content, which are arguably more relevant to separating forced signals and variability over the observational record (e.g., Palmer et al. 2007; Frankcombe et al. 2015). The standard deviation of 51-yr heat content trends (relevant to the modern observational record) are $10 \%-15 \%$ smaller in the temperature coordinate than the depth coordinate down to $p \approx 60 \%$ (cf. solid red and black lines in Fig. 12c), suggesting that this coordinate does have a small advantage over the depth coordinate for separating forced trends on these time scales. Over shorter time scales, such as for $15-\mathrm{yr}$ heat content trends (relevant to the Argo period, dashed lines in Figs. 12c,f) the temperature coordinate is again advantageous over the depth coordinate in the upper, warmer ocean $(p<30 \%$, compare red and black dashed lines in Fig. 12b), where trends are reduced by up to $30 \%$.

\section{Conclusions}

Using a rigorous volume-percentile framework applied to temperature-, depth-, and latitude-based coordinates (see section 3) we have quantified the projection of internal $\mathrm{OHC}$ variability in the ACCESS-CM2 PI control simulation into Eulerian depth and latitude coordinates and into a watermass-based temperature coordinate. The temperature-based coordinate filters out adiabatic variability by definition, resulting in a $\sim 50 \%$ reduction in temperature variance at ENSO-dominated interannual frequencies compared to the depth-based coordinate (see section 4a and Table 1). However, at decadal to centennial frequencies (dominant outside of the surface/warmest $10 \%$ of the ocean volume), where temperature variability is related to variations in the GMOC (section $4 b$ ), temperature variance in the diabatic temperature coordinate is comparable or greater than that in the Eulerian depth coordinate, highlighting the importance of diabatic processes at low frequencies. This suggests that a good representation of these diabatic processes, among many other factors, is needed in order to improve the simulation of decadal variability (which is often too weak in models; Ault et al. 2012; Kociuba and Power 2015; Yan et al. 2018).

A spectral analysis of the heat budget in the three coordinates supported the above conclusions and revealed the emergence of quasi-steady-state balances at low frequencies between surface forcing and mixing in the temperature coordinate, advection and mixing in the depth coordinate and advection and surface forcing in the latitude coordinate (Fig. 11). At all frequencies, variability in the temperature coordinate was more directly related to variability in the surface forcing than in either depth or latitude coordinate, where advective vertical or meridional ocean heat transport variability played the dominant role. Our analysis also revealed the tendency for anticorrelations between lowfrequency variability at high latitudes, cold temperatures, and below $2000 \mathrm{~m}$ with the global OHC (the variable of interest for Earth's energy budget on climate-relevant time scales), suggesting that observations that do not sample these regions may overestimate low-frequency global $\mathrm{OHC}$ variability (section 5 ).

Beyond the removal of the adiabatic portion of ENSOrelated interannual variability, the use of a temperature coordinate (compared to the depth coordinate) resulted in only slightly improved correlation estimates of global OHC variability. The temperature coordinate did show a $10 \%-15 \%$ reduction in the amplitude of internal 51-yr linear OHC trends (a period with length relevant to the modern observational record), and a somewhat larger up to $30 \%$ reduction in $15-y r$ linear OHC trends (relevant to the Argo period), compared to the depth coordinate in the 
(a)

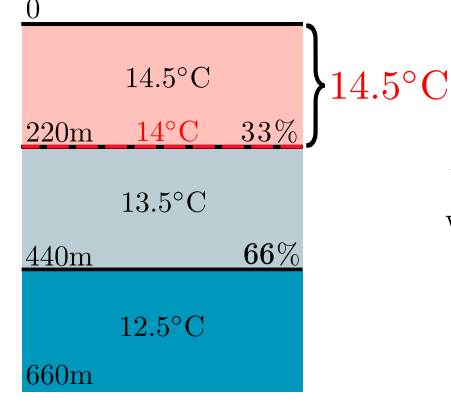

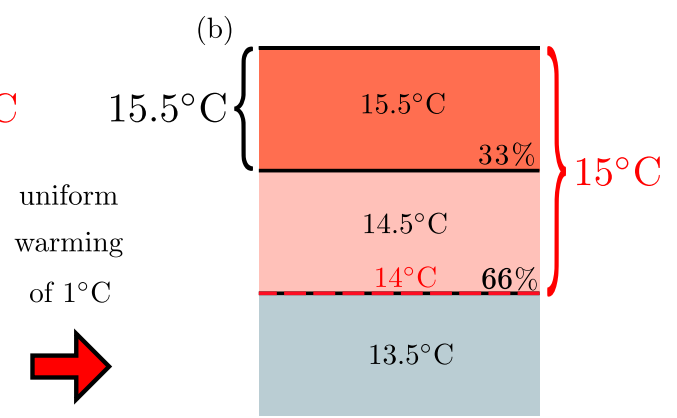

FIG. A1. An idealized example demonstrating the utility of the volume percentile approach. (a) A stably stratified ocean with three regions of uniform temperature $14.5^{\circ}, 13.5^{\circ}$, and $12.5^{\circ} \mathrm{C}$ and equal volume (reaching depths of 220,440 , and $660 \mathrm{~m}$, respectively). The average temperature of the volume warmer than the $14^{\circ}$ isotherm (red dashed line in both panels), above $220 \mathrm{~m}$ and in the top $33 \%$ temperature and depth percentiles is $14.5^{\circ} \mathrm{C}$ (indicated by the external curly brace). (b) If the idealized ocean is warmed uniformly by $1^{\circ} \mathrm{C}$ then the volume of water warmer than $14^{\circ} \mathrm{C}$ is doubled. Therefore, the average temperature of this volume warms by only $0.5^{\circ} \mathrm{C}$, to $15^{\circ} \mathrm{C}$ (red external curly brace), in contrast to the $1^{\circ} \mathrm{C}$ warming of the average temperature of the upper $220 \mathrm{~m}$. The use of volume percentiles avoids this issue by maintaining constant volumes. That is, the warmest (and shallowest) $33 \%$ of the ocean by volume warms by $1^{\circ} \mathrm{C}$ [black external curly bracket in (b)].

upper/warmer half of the ocean (Fig. 12c). We emphasize that these results are based on complete knowledge of the spatial and temporal variability of temperature (here, from a model). The temperature-coordinate analysis may be more advantageous for estimating trends from temporally and spatially intermittent observations by reducing sampling bias associated with adiabatic heaving (Palmer et al. 2007; Palmer and Haines 2009). Evaluation of the potential benefits of a temperature coordinate in the context of synthetic sampling of climate model data (e.g., Allison et al. 2019) would make for an interesting follow-up study. We also note that a climate change signal may project differently onto the various coordinates than the internal climate variability considered here (also see Sohail et al. 2021). Finally, it is important to note that our analysis has focused on globally averaged variability and is distinct from local analyses (such as heave and spice decompositions, e.g., Bindoff and McDougall 1994; Desbruyères et al. 2017) where the balance of driving processes may be different.

Acknowledgments. We acknowledge the World Climate Research Programme, which, through its Working Group on Coupled Modeling, coordinated and promoted CMIP6. We thank the climate modeling groups for producing and making available their model output, the Earth System Grid Federation (ESGF) for archiving the data and providing access, and the multiple funding agencies who support CMIP6 and ESGF. Data analysis was undertaken using facilities at the National Computational Infrastructure (NCI), which is supported by the Australian government. We thank Abhishek Savita for useful assistance with the ACCESS-CM2 data access. The authors are supported by the Australian Research Council (ARC)'s Centre of Excellence for Climate Extremes. We acknowledge support from ARC Awards DP190101173 and DE21010004.
Data availability statement. The data required to reproduce the results in this article are published online (Holmes et al. 2021b, https://dx.doi.org/10.5281/zenodo.5728574).

\section{APPENDIX A}

\section{An Idealized Example Demonstrating the Utility of Volume Percentiles}

In this appendix we demonstrate the utility of the volume-percentile framework over a regular temperature- or depth-coordinate comparative analysis. Consider an idealized, stably stratified ocean consisting of three vertically stacked regions of uniform temperature and equal volume (Fig. A1a), where the top layer is chosen for demonstration purposes to be representative of the 220-m depth and $14^{\circ} \mathrm{C}$ isotherm used by Palmer et al. (2007). Under a uniform warming of $1^{\circ} \mathrm{C}$ across the whole ocean, the volume of water above $220 \mathrm{~m}$, corresponding also to the top $33 \%$ volume-percentiles in both depth and temperature, warms by $1^{\circ} \mathrm{C}$. However, the average temperature of all water warmer than $14^{\circ} \mathrm{C}$ warms only by $0.5^{\circ} \mathrm{C}$, because the $14^{\circ} \mathrm{C}$ isotherm moves downward and thus the volume of water warmer than $14^{\circ} \mathrm{C}$ doubles. This change is not representative of the uniform change in ocean temperature, and therefore biases any comparison of heat content variability between the regular temperature and depth coordinates. While this is an extreme example, even smaller changes in volume can have an impact (including on the outcrop location of the surface of interest, and thus the fraction of surface forcing anomalies absorbed, e.g., Sohail et al. 2021). No matter what the actual volume changes are, the volume-percentile approach avoids these issues by considering constant volumes. Similar considerations motivated the relative heat content approach of Palmer 
and Haines (2009) and the internal heat content approach of Holmes et al. (2019).

\section{APPENDIX B}

\section{The Heat Budget in Temperature-Percentile Coordinates}

We write the "internal" heat content budget of temperature layers, Eq. (12) of Holmes et al. (2019), as

$$
\begin{aligned}
\frac{\partial \mathcal{H}_{I}}{\partial t}\left(\Theta^{*}, t\right)= & \underbrace{\mathcal{F}^{T+R}\left(\Theta^{*}, t\right)+\mathcal{F}^{V}\left(\Theta^{*}, t\right)-\mathcal{J}^{V}\left(\Theta^{*}, t\right) \rho_{0} c_{p} \Theta^{*}}_{\mathcal{F}\left(\Theta^{*}, t\right)} \\
& +\mathcal{M}\left(\Theta^{*}, t\right) .
\end{aligned}
$$

In Eq. (B1) $\mathcal{F}^{T+R}\left(\Theta^{*}, t\right)+\mathcal{F}^{V}\left(\Theta^{*}, t\right)$ is the total heat flux into waters warmer than $\Theta^{*}$ from surface heat fluxes, where the component associated with all surface volume fluxes is treated separately as $\mathcal{F}^{V}$. The term $\mathcal{J}^{V}$ is the total surface volume flux into the same waters, and $\mathcal{M}$ is the heat flux across the $\Theta^{*}$ isotherm due to mixing. Here, we have grouped the total contribution of surface heat and volume fluxes to the "internal" heat content tendency into $\mathcal{F}\left(\Theta^{*}, t\right)$ [equivalent to $\mathcal{F}\left(\Theta^{*}, t\right)+\mathcal{P}_{I}\left(\Theta^{*}, t\right)$ in the notation of Holmes et al. 2019]. The internal heat content tendency is given by

$$
\frac{\partial \mathcal{H}_{I}}{\partial t}\left(\Theta^{*}, t\right)=\frac{\rho_{0} C_{p} V}{100} \int_{\Theta^{*}}^{\infty} \frac{\partial p_{\Theta}}{\partial t}\left(\Theta^{\prime}, t\right) d \Theta^{\prime},
$$

where we have used $\mathcal{V}\left(\Theta^{*}, t\right)=p_{\Theta} V / 100$ in Eq. (11) of Holmes et al. (2019). Using the chain rule and the inversion relationship Eq. (4) (also see section 2.2 of Sohail et al. 2021),

$$
\frac{\partial p_{\Theta}}{\partial t}\left(\Theta^{*}, t\right)=\left(\frac{\partial \Theta_{\Theta}}{\partial p}\right)^{-1} \frac{\partial \Theta_{\Theta}}{\partial t}(p, t) .
$$

Using Eq. (B3) in Eq. (B2) yields

$$
\frac{\partial \mathcal{H}_{I}}{\partial t}\left(\Theta^{*}, t\right)=\frac{\rho_{0} C_{p} V}{100} \int_{0}^{p_{\Theta}\left(\Theta^{*}, t\right)} \frac{\partial \Theta_{\Theta}}{\partial t}\left(p^{\prime}, t\right) d p^{\prime},
$$

showing that, with $p$ identified as $p_{\Theta}\left(\Theta^{*}, t\right),\left(\partial \mathcal{H}_{I} / \partial t\right)\left(\Theta^{*}, t\right)$ in temperature coordinates is equivalent to $(\partial \mathcal{H} / \partial t)(p, t)$ in temperature-percentile coordinates [Eq. (5)]. Therefore, the heat budget [Eq. (6)] for $\mathcal{H}(p, t)$ is equivalent to Eq. (B1) with $\mathcal{F}(p, t)=\mathcal{F}\left[\Theta_{\Theta}(p, t), t\right]$ and $\mathcal{M}(p, t)=\mathcal{M}\left[\Theta_{\Theta}(p, t), t\right]$. Specifically, this equivalence shows that the heat flux associated with the across-isotherm volume flux $\left[\mathcal{G}\left(\Theta^{*}, t\right)\right.$ in Holmes et al. 2019] does not appear when considering the heat budget in temperature-percentile coordinates. This is because temperature-percentiles have a constant volume by construction. While net volume fluxes across a given temperature-percentile surface can be nonzero when such a flux is exactly balanced by surface volume fluxes, the associated heat flux is accounted for by the correction to the surface forcing term $-\mathcal{J}^{V}\left(\Theta^{*}, t\right) \rho_{0} c_{p} \Theta^{*}$ contained in $\mathcal{F}\left(\Theta^{*}, t\right)$ in Eq. (B1).

\section{REFERENCES}

Allison, L. C., C. D. Roberts, M. D. Palmer, L. Hermanson, R. E. Killick, N. A. Rayner, D. M. Smith, and M. B. Andrews, 2019: Towards quantifying uncertainty in ocean heat content changes using synthetic profiles. Environ. Res. Lett., 14, 084037, https://doi.org/10.1088/1748-9326/ab2b0b.

Ault, T. R., J. E. Cole, and S. St. George, 2012: The amplitude of decadal to multidecadal variability in precipitation simulated by state-of-the-art climate models. Geophys. Res. Lett., 39, L21705, https://doi.org/10.1029/2012GL053424.

Bi, D., and Coauthors, 2020: Configuration and spin-up of ACCESS-CM2, the new generation Australian Community Climate and Earth System Simulator Coupled Model. J. South. Hemisphere Earth Syst. Sci., 70, 225-251, https://doi. org/10.1071/ES19040.

Bindoff, N. L., and T. J. McDougall, 1994: Diagnosing climate change and ocean ventilation using hydrographic data. $J$. Phys. Oceanogr., 24, 1137-1152, https://doi.org/10.1175/15200485(1994)024<1137:DCCAOV > 2.0.CO;2.

Bryden, H. L., W. E. Johns, B. A. King, G. McCarthy, E. L. McDonagh, B. I. Moat, and D. A. Smeed, 2020: Reduction in ocean heat transport at $26^{\circ} \mathrm{N}$ since 2008 cools the eastern subpolar gyre of the North Atlantic Ocean. J. Climate, 33, 16771689, https://doi.org/10.1175/JCLI-D-19-0323.1.

Cane, M. A., and S. E. Zebiak, 1985: A theory for El Niño and the Southern Oscillation. Science, 228, 1085-1087, https://doi. org/10.1126/science.228.4703.1085.

Cheng, L., K. E. Trenberth, J. T. Fasullo, M. Mayer, M. Balmaseda, and J. Zhu, 2019: Evolution of ocean heat content related to ENSO. J. Climate, 32, 3529-3556, https://doi.org/10.1175/JCLID-18-0607.1.

Delworth, T. L., and F. Zeng, 2012: Multicentennial variability of the Atlantic meridional overturning circulation and its climatic influence in a 4000 year simulation of the GFDL CM2.1 climate model. Geophys. Res. Lett., 39, L13702, https://doi.org/10.1029/2012GL052107.

Deppenmeier, A.-L., F. O. Bryan, W. Kessler, and L. Thompson, 2021: Modulation of cross-isothermal velocities with ENSO in the tropical Pacific cold tongue. J. Phys. Oceanogr., 51, 1559-1574, https://doi.org/10.1175/JPO-D-20-0217.1.

Desbruyères, D., E. L. McDonagh, B. A. King, and V. Thierry, 2017: Global and full-depth ocean temperature trends during the early twenty-first century from Argo and repeat hydrography. J. Climate, 30, 1985-1997, https://doi.org/10.1175/JCLID-16-0396.1.

Dias, F. B., C. M. Domingues, S. J. Marsland, S. Griffies, S. Rintoul, R. Matear, and R. Fiedler, 2020: On the superposition of mean advective and eddy-induced transports in global ocean heat and salt budgets. J. Climate, 33, 1121-1140, https://doi.org/10.1175/JCLI-D-19-0418.1.

Dong, B., and R. T. Sutton, 2005: Mechanism of interdecadal thermohaline circulation variability in a coupled ocean: Atmosphere GCM. J. Climate, 18, 1117-1135, https://doi.org/ 10.1175/JCLI3328.1.

Drijfhout, S., A. Blaker, S. Josey, A. Nurser, B. Sinha, and M. Balmaseda, 2014: Surface warming hiatus caused by increased heat uptake across multiple ocean basins. Geophys. Res. Lett., 41, 7868-7874, https://doi.org/10.1002/2014GL061456.

England, M. H., and Coauthors, 2014: Recent intensification of wind-driven circulation in the Pacific and the ongoing warming hiatus. Nat. Climate Change, 4, 222-227, https://doi.org/10. 1038/nclimate2106. 
Eyring, V., S. Bony, G. A. Meehl, C. A. Senior, B. Stevens, R. J. Stouffer, and K. E. Taylor, 2016: Overview of the Coupled Model Intercomparison Project Phase 6 (CMIP6) experimental design and organization. Geosci. Model Dev., 9, 19371958, https://doi.org/10.5194/gmd-9-1937-2016.

Frankcombe, L. M., S. McGregor, and M. H. England, 2015: Robustness of the modes of indo-Pacific sea level variability. Climate Dyn., 45, 1281-1298, https://doi.org/10.1007/s00382014-2377-0.

Gent, P. R., and J. C. McWilliams, 1990: Isopycnal mixing in ocean circulation models. J. Phys. Oceanogr., 20, 150-155, https://doi.org/10.1175/1520-0485(1990)020<0150:IMIOCM >2. $0 . \mathrm{CO} ; 2$.

Gregory, J. M., 2000: Vertical heat transports in the ocean and their effect on time-dependent climate change. Climate Dyn., 16, 501-515, https://doi.org/10.1007/s003820000059.

Griffies, S. M., 2012: Elements of the Modular Ocean Model (MOM). GFDL Ocean Group Tech. Rep. 7, NOAA/Geophysical Fluid Dynamics Laboratory, 620 pp.

_ A. Ananadesikan, R. C. Pacanowski, V. Larichev, J. K. Dukowicz, and R. D. Smith, 1998: Isoneutral diffusion in a $z$ coordinate ocean model. J. Phys. Oceanogr., 28, 805-830, https://doi.org/10.1175/1520-0485(1998)028<0805:IDIAZC $>2$. $0 . \mathrm{CO} ; 2$.

- , and Coauthors, 2015: Impacts on ocean heat from transient mesoscale eddies in a hierarchy of climate models. J. Climate, 28, 952-977, https://doi.org/10.1175/JCLI-D-14-00353.1.

Hieronymus, M., and J. Nycander, 2020: Interannual variability of the overturning and energy transport in the atmosphere and ocean during the late twentieth century with implications for precipitation and sea level. J. Climate, 33, 317-338, https://doi. org/10.1175/JCLI-D-19-0204.1.

_, J. Nilsson, and J. Nycander, 2014: Water mass transformation in salinity-temperature space. J. Phys. Oceanogr., 44, 2547-2568, https://doi.org/10.1175/JPO-D-13-0257.1.

Holmes, R. M., J. D. Zika, and M. H. England, 2019: Diathermal heat transport in a global ocean model. J. Phys. Oceanogr., 49, 141-161, https://doi.org/10.1175/JPO-D-18-0098.1.

,,-- S. M. Griffies, A. M. Hogg, A. E. Kiss, and M. H. England, 2021a: The geography of numerical mixing in a suite of global ocean models. J. Adv. Model. Earth Syst., 13, e2020MS002333, https://doi.org/10.1029/2020MS002333.

_, T. Sohail, and J. Zika, 2021b: Adiabatic and diabatic signatures of ocean temperature variability - ACCESS-CM2 processing/plotting code and processed data. Zenodo, https:// dx.doi.org/10.5281/zenodo.5728574.

Huguenin, M. F., R. M. Holmes, and M. H. England, 2020: Key role of diabatic processes in regulating warm water volume variability over ENSO events. J. Climate, 33, 9945-9964, https://doi.org/10.1175/JCLI-D-20-0198.1.

Irving, D., W. Hobbs, J. Church, and J. Zika, 2020: A mass and energy conservation analysis of drift in the CMIP6 ensemble. J. Climate, 34, 3157-3170, https://doi.org/10.1175/JCLI-D-200281.1.

Jayne, S. R., and J. Marotzke, 2001: The dynamics of ocean heat transport variability. Rev. Geophys., 39, 385-411, https://doi. org/10.1029/2000RG000084.

Jin, F.-F., 1997: An equatorial ocean recharge paradigm for ENSO. Part I: Conceptual model. J. Atmos. Sci., 54, 811-829, https://doi.org/10.1175/1520-0469(1997)054<0811:AEORPF $>2$. $0 . \mathrm{CO} ; 2$.
Jochum, M., 2009: Impact of latitudinal variations in vertical diffusivity on climate simulations. J. Geophys. Res., 114, C01010, https://doi.org/10.1029/2008JC005030.

Johnson, G. C., and A. N. Birnbaum, 2017: As El Niño builds, Pacific warm pool expands, ocean gains more heat. Geophys. Res. Lett., 44, 438-445, https://doi.org/10.1002/2016GL071767.

Kociuba, G., and S. B. Power, 2015: Inability of CMIP5 models to simulate recent strengthening of the Walker circulation: Implications for projections. J. Climate, 28, 20-35, https://doi. org/10.1175/JCLI-D-13-00752.1.

Kosaka, Y., and S.-P. Xie, 2016: The tropical Pacific as a key pacemaker of the variable rates of global warming. Nat. Geosci., 9, 669-673, https://doi.org/10.1038/ngeo2770.

Large, W. G., J. C. McWilliams, and S. C. Doney, 1994: Oceanic vertical mixing: A review and a model with a nonlocal boundary layer parameterization. Rev. Geophys., 32, 363-403, https://doi.org/10.1029/94RG01872.

Maher, N., M. England, A. Sen Gupta, and P. Spence, 2017: Role of the Pacific trade winds in driving ocean temperatures during the recent hiatus and projections for a wind reversal. Climate Dyn., 51, 321-336, https://doi.org/10.1007/s00382-0173923-3.

Mayer, M., L. Haimberger, and M. A. Balmaseda, 2014: On the energy exchange between tropical ocean basins related to ENSO. J. Climate, 27, 6393-6403, https://doi.org/10.1175/ JCLI-D-14-00123.1.

— J. T. Fasullo, K. E. Trenberth, and L. Haimberger, 2016: ENSO-driven energy budget perturbations in observations and CMIP models. Climate Dyn., 47, 4009-4029, https://doi. org/10.1007/s00382-016-3057-z.

McDougall, T. J., 2003: Potential enthalpy: A conservative oceanic variable for evaluating heat content and heat fluxes. J. Phys. Oceanogr., 33, 945-963, https://doi.org/10.1175/1520-0485 (2003)033<0945:PEACOV>2.0.CO;2.

_ , and P. M. Barker, 2011: Getting started with TEOS-10 and the Gibbs Seawater (GSW) oceanographic toolbox. SCOR/ IAPSO WG127, 28 pp.

McGregor, S., P. Spence, F. U. Schwarzkopf, M. H. England, A. Santoso, W. S. Kessler, A. Timmermann, and C. W. Boning, 2014: ENSO-driven interhemispheric Pacific mass transports. J. Geophys. Res. Oceans, 119, 6221-6237, https://doi.org/10. 1002/2014JC010286.

Menary, M. B., W. Park, K. Lohmann, M. Vellinga, M. D. Palmer, M. Latif, and J. H. Jungclaus, 2012: A multimodel comparison of centennial Atlantic meridional overturning circulation variability. Climate Dyn., 38, 2377-2388, https://doi.org/10. 1007/s00382-011-1172-4.

Morrison, A. K., O. A. Saenko, A. M. Hogg, and P. Spence, 2013: The role of vertical eddy flux in Southern Ocean heat uptake. Geophys. Res. Lett., 40, 5445-5450, https://doi.org/10.1002/ 2013GL057706.

Munk, W. H., 1966: Abyssal recipes. Deep-Sea Res., 13, 707-730, https://doi.org/10.1016/0011-7471(66)90602-4.

Oldenburg, D., R. C. J. Wills, K. C. Armour, L. Thompson, and L. C. Jackson, 2021: Mechanisms of low-frequency variability in North Atlantic Ocean heat transport and AMOC. J. Climate, 34, 4733-4755, https://doi.org/10.1175/JCLI-D-20-0614.1.

Palmer, M. D., and K. Haines, 2009: Estimating oceanic heat content change using isotherms. J. Climate, 22, 4953-4969, https://doi.org/10.1175/2009JCLI2823.1.

—, and D. J. McNeall, 2014: Internal variability of Earth's energy budget simulated by CMIP5 climate models. Environ. 
Res. Lett., 9, 034016, https://doi.org/10.1088/1748-9326/9/3/ 034016.

— K. Haines, S. F. B. Tett, and T. J. Ansell, 2007: Isolating the signal of ocean global warming. Geophys. Res. Lett., 34, L23610, https://doi.org/10.1029/2007GL031712.

— , S. A. Good, K. Haines, N. A. Rayner, and P. A. Stott, 2009: A new perspective on warming of the global oceans. Geophys. Res. Lett., 36, L20709, https://doi.org/10.1029/ 2009GL039491.

Park, W., and M. Latif, 2008: Multidecadal and multicentennial variability of the meridional overturning circulation. Geophys. Res. Lett., 35, L22703, https://doi.org/10.1029/2008GL035779.

Rathore, S., N. L. Bindoff, H. E. Phillips, and M. Feng, 2020: Recent hemispheric asymmetry in global ocean warming induced by climate change and internal variability. Nat. Commun., 11, 2008, https://doi.org/10.1038/s41467-020-15754-3.

Redi, M. H., 1982: Oceanic isopycnal mixing by coordinate rotation. J. Phys. Oceanogr., 12, 1154-1158, https://doi.org/10. 1175/1520-0485(1982)012<1154:OIMBCR > 2.0.CO;2.

Roberts, C. D., M. D. Palmer, R. P. Allan, D. Desbruyeres, P. Hyder, C. Liu, and D. Smith, 2017: Surface flux and ocean heat transport convergence contributions to seasonal and interannual variations of ocean heat content. J. Geophys. Res. Oceans, 122, 726-744, https://doi.org/10.1002/2016JC012278.

Roemmich, D., and J. Gilson, 2011: The global ocean imprint of ENSO. Geophys. Res. Lett., 38, L13606, https://oi.org/10. 1029/2011GL047992.

—, J. Church, J. Gilson, D. Monselesan, P. Sutton, and S. Wijffels, 2015: Unabated planetary warming and its ocean structure since 2006. Nat. Climate Change, 5, 240-245, https:// doi.org/10.1038/nclimate2513.

Savita, A., J. D. Zika, C. M. Domingues, S. J. Marsland, G. D. Evans, F. B. Dias, R. M. Holmes, and A. M. Hogg, 2021: Super residual circulation: A new perspective on ocean vertical heat transport. J. Phys. Oceanogr., 51, 2443-2462, https:// doi.org/10.1175/JPO-D-21-0008.1.

Simmons, H. L., S. R. Jayne, L. C. S. Laurent, and A. J. Weaver, 2004: Tidally driven mixing in a numerical model of the ocean general circulation. Ocean Modell., 6, 245-263, https:// doi.org/10.1016/S1463-5003(03)00011-8.

Sohail, T., D. B. Irving, J. D. Zika, R. M. Holmes, and J. A. Church, 2021: Fifty year trends in global ocean heat content traced to surface heat fluxes in the sub-polar ocean. Geophys. Res. Lett., 48, e2020GL091439, https://doi.org/10.1029/ 2020 GL091439.

Solomon, H., 1971: On the representation of isentropic mixing in ocean circulation models. J. Phys. Oceanogr., 1, 233-234,
https://doi.org/10.1175/1520-0485(1971)001<0233:OTROIM >2. $0 . \mathrm{CO} ; 2$.

Stevenson, J. W., and P. P. Niiler, 1983: Upper ocean heat budget during the Hawaii-to-Tahiti shuttle experiment. J. Phys. Oceanogr., 13, 1894-1907, https://doi.org/10.1175/1520-0485 (1983)013<1894:UOHBDT>2.0.CO;2.

Toole, J. M., H.-M. Zhang, and M. J. Caruso, 2004: Time-dependent internal energy budgets of the tropical warm water pools. $J$. Climate, 17, 1398-1410, https://doi.org/10.1175/1520-0442(2004) 017<1398:TIEBOT>2.0.CO;2.

Trenberth, K. E., 2020: ENSO in the global climate system. El Niño Southern Oscillation in a Changing Climate, Geophys. Monogr., Vol. 253, Amer. Geophys. Union, 21-37, https://doi. org/10.1002/9781119548164.ch2.

- , and J. M. Caron, 2001: Estimates of meridional atmosphere and ocean heat transports. J. Climate, 14, 3433-3443, https:// doi.org/10.1175/1520-0442(2001)014<3433:EOMAAO>2.0.CO;2.

- - J. T. Fasullo, K. von Schuckmann, and L. Cheng, 2016: Insights into Earth's energy imbalance from multiple sources. J. Climate, 29, 7495-7505, https://doi.org/10.1175/JCLI-D-160339.1.

von Schuckmann, K., and Coauthors, 2020: Heat stored in the Earth system: Where does the energy go? Earth Syst. Sci. Data, 12, 2013-2041, https://doi.org/10.5194/essd-12-2013-2020.

Warner, S. J., and J. N. Moum, 2019: Feedback of mixing to ENSO phase change. Geophys. Res. Lett., 46, 13920-13927, https://doi.org/10.1029/2019GL085415.

Wolfe, C. L., P. Cessi, J. L. McClean, and M. E. Maltrud, 2008: Vertical heat transport in eddying ocean models. Geophys. Res. Lett., 35, L23605, https://doi.org/10.1029/2008GL036138.

Yan, X., R. Zhang, and T. R. Knutson, 2018: Underestimated AMOC variability and implications for AMV and predictability in CMIP models. Geophys. Res. Lett., 45, 4319-4328, https://doi.org/10.1029/2018GL077378.

Zika, J. D., W. P. Sijp, and M. H. England, 2013: Vertical heat transport by ocean circulation and the role of mechanical and haline forcing. J. Phys. Oceanogr., 43, 2095-2112, https://doi. org/10.1175/JPO-D-12-0179.1.

—, N. Skliris, A. G. Nurser, S. A. Josey, L. Mudryk, F. Laliberté, and R. Marsh, 2015: Maintenance and broadening of the ocean's salinity distribution by the water cycle. J. Climate, 28, 9550-9560, https://doi.org/10.1175/JCLI-D-15-0273.1.

- J. M. Gregory, E. L. McDonagh, A. Marzocchi, and L. Clément, 2021: Recent water mass changes reveal mechanisms of ocean warming. J. Climate, 34, 3461-3479, https:// doi.org/10.1175/JCLI-D-20-0355.1. 